\title{
Synthesis of mesoporous ZSM-5 zeolite encapsulated in an ultrathin protective shell of silicalite-1 for MTH conversion
}

Goodarzi, Farnoosh; Herrero, Irene Pinilla; Kalantzopoulos, Georgios N.; Svelle, Stian; Lazzarini, Andrea; Beato, Pablo; Olsbye, Unni; Kegnæs, Søren

\section{Published in:}

Microporous and Mesoporous Materials

Link to article, DOI:

10.1016/j.micromeso.2019.109730

Publication date:

2020

Document Version

Peer reviewed version

Link back to DTU Orbit

Citation (APA):

Goodarzi, F., Herrero, I. P., Kalantzopoulos, G. N., Svelle, S., Lazzarini, A., Beato, P., Olsbye, U., \& Kegnæs, S. (2020). Synthesis of mesoporous ZSM-5 zeolite encapsulated in an ultrathin protective shell of silicalite- 1 for MTH conversion. Microporous and Mesoporous Materials, 292, [109730].

https://doi.org/10.1016/j.micromeso.2019.109730

\section{General rights}

Copyright and moral rights for the publications made accessible in the public portal are retained by the authors and/or other copyright owners and it is a condition of accessing publications that users recognise and abide by the legal requirements associated with these rights.

- Users may download and print one copy of any publication from the public portal for the purpose of private study or research.

- You may not further distribute the material or use it for any profit-making activity or commercial gain

- You may freely distribute the URL identifying the publication in the public portal 


\section{Journal Pre-proof}

Synthesis of mesoporous ZSM-5 zeolite encapsulated in an ultrathin protective shell of silicalite-1 for MTH conversion

Farnoosh Goodarzi, Irene Pinilla Herrero, Georgios N. Kalantzopoulos, Stian Svelle, Andrea Lazzarini, Pablo Beato, Unni Olsbye, Søren Kegnæs

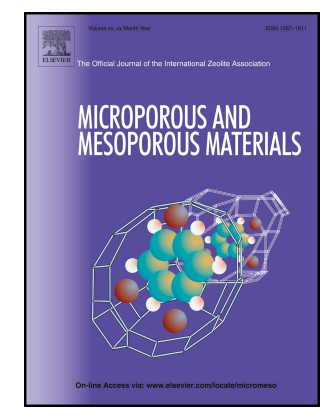

PII:

S1387-1811(19)30587-6

DOI:

https://doi.org/10.1016/j.micromeso.2019.109730

Reference: MICMAT 109730

To appear in: Microporous and Mesoporous Materials

Received Date: 10 July 2019

Revised Date: 27 August 2019

Accepted Date: 15 September 2019

Please cite this article as: F. Goodarzi, I.P. Herrero, G.N. Kalantzopoulos, S. Svelle, A. Lazzarini, P. Beato, U. Olsbye, Sø. Kegnæs, Synthesis of mesoporous ZSM-5 zeolite encapsulated in an ultrathin protective shell of silicalite-1 for MTH conversion, Microporous and Mesoporous Materials (2019), doi: https://doi.org/10.1016/j.micromeso.2019.109730.

This is a PDF file of an article that has undergone enhancements after acceptance, such as the addition of a cover page and metadata, and formatting for readability, but it is not yet the definitive version of record. This version will undergo additional copyediting, typesetting and review before it is published in its final form, but we are providing this version to give early visibility of the article. Please note that, during the production process, errors may be discovered which could affect the content, and all legal disclaimers that apply to the journal pertain.

(C) 2019 Published by Elsevier Inc. 
Graphical abstract

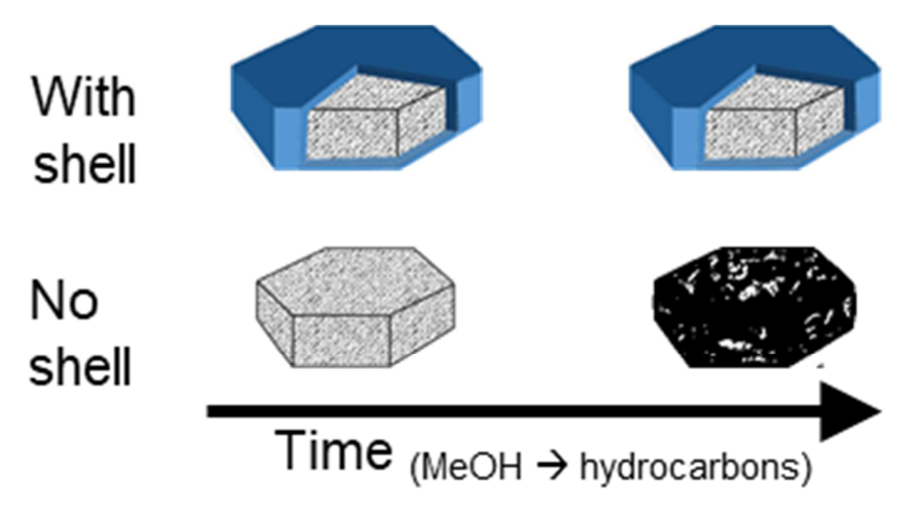




\section{Synthesis of mesoporous ZSM-5 zeolite}

\section{encapsulated in an ultrathin protective shell of}

\section{silicalite-1 for MTH conversion}

Farnoosh Goodarzi, ${ }^{a}$ Irene Pinilla Herrero, ${ }^{b}$ Georgios N. Kalantzopoulos, ${ }^{b}$ Stian Svelle, ${ }^{b}$ Andrea Lazzarini, ${ }^{b}$ Pablo Beato, ${ }^{c}$ Unni Olsbye, ${ }^{b}$ Søren Kegness ${ }^{*}, a$

${ }^{a}$ DTU chemistry, Technical University of Denmark, Kemitorvet 207, 2800 Kgs, Lyngby, Denmark.

*Corresponding author Email: skk@kemi.dtu.dk, Tel: +45 45252402

${ }^{\mathrm{b}}$ Department of Chemistry, University of Oslo, P.O. Box 1033 Blindern, 0315 Oslo, Norway.

${ }^{\mathrm{c}}$ Haldor Topsøe A/S, Haldor Topsøes Allé 1, 2800 Kgs, Lyngby, Denmark. 


\begin{abstract}
Coke formation is a major reason in deactivation of acidic zeolite catalysts in industrial processes such as methanol to hydrocarbons conversion. Protecting the surface of acidic zeolite with an inert porous shell can greatly hinder the coke formation on the surface, and hence boost the lifetime of the catalyst. In this work, a solid-state steam-assisted method for synthesis of such optimized protective shell (silicate-1, $\square 15 \mathrm{~nm}$ thickness) is designed. This general and simple protocol can be applied to acidic zeolite catalysts to improve their catalytic lifetime. The silicalite-1 shell is synthesized on mesoporous ZSM-5 zeolite to explore its catalytic activity in methanol to hydrocarbons conversion. XPS and TEM analysis confirm the coverage of mesoporous zeolite crystals by non-acidic shell. In addition, nitrogen physisorption shows the accessibility of mesoporous ZSM-5 via microporous silicalite-1 network. Applying this protective shell increases the lifetime of the catalyst by $100 \%$ and its conversion capacity by $130 \%$, in comparison to mesoporous ZSM-5 without the shell. The controlled formation of thin layer of microporous silicalite-1 around mesoporous ZSM-5 crystals (without growth of individual silicalite-1) accounts for enhanced catalytic improvement.
\end{abstract}

KEYWORDS. Shell, coke, zeolite, mesoporous, heterogeneous catalysis, methanol 


\section{Introduction}

Zeolites play an outstanding role in the heterogeneous catalysis industry as microporous crystalline aluminosilicate materials. Their remarkable applicability relies on their particular properties such as high thermal stability, large surface area, strong acidity and a well-defined microporous structure, which leads to shape selectivity in reactions [1-4]. In particular, ZSM-5 zeolite, which has the MFI topology with 3-dimensional channels (straight channels of 5.3×5.6 ̊ and sinusoidal channels of 5.1 $\times 5.5 \AA$ ) [5] is frequently used in hydrocarbon conversions, e.g., cracking, alkylation, isomerization and methanol to hydrocarbons [6-9]. Even if ZSM-5 zeolite is proven to be an efficient catalyst with a positive impact in a good number of industrial processes, there is still room for improvements when it comes to their applicability. In fact, ZSM-5 zeolite suffers from deactivation due to rapid coke deposition especially in the outer rim of the zeolite crystals. Coke can be defined as any kind of large organic compound that challenges the diffusion to the zeolite active sites causing their deactivation. This can occur either by irreversible adsorption on the internal surface of the micropores blocking the accessibility of the reactants to the acid sites or by coating the outer surface of the crystal blocking the entrance to the internal pore network. This phenomenon results in the progressive decrease of the zeolite catalytic performance. Hence, regeneration of the catalyst becomes essential, adding cost to the process $[8,10]$. Therefore, it is crucial to address this issue and improve the structural features in the microporous zeolite that can assist to minimize coke deposition and prolong the lifetime of the catalyst. 
The transport in and out of the micropores is delayed because of the diffusion barrier, which can lead to secondary reactions of the reactants and products towards undesired byproducts like coke precursors [11-13]. An alternative that tackles the mass transfer issue in ZSM-5 zeolite is to enhance the diffusion in the system, either by the introduction of a secondary porosity in the zeolite to achieve hierarchical porous structure or by the decrease of the crystal size to nanometer scale, thereby shortening the diffusion paths [14-18]. Mesoporous ZSM-5 zeolite with hierarchical pore structure provides a shorter diffusion path, thus enhancing the accessibility to the active sites and improving the resistance to deactivation by coke formation [19-22]. The mesoporous system can be created in the zeolite either by post-synthetic treatment such as alkali treatment and steaming [23-25] or by direct synthesis using hard/soft templates [26-30].

Ideally, the proposed solution should address the coking issue, but the effect of acid site concentration on the external surfaces of zeolite crystals cannot be neglected. These external acid sites cause faster coke formation and blockage of the pore opening window due to lack of shape selectivity for the reactions that take place on the outer surface [31]. Another strategy that has been investigated to resolve this problem is controlling the external surface acidity by covering the zeolite crystal with a non-active layer such as silicalite-1 [32-36]. Silicalite-1 shell has been reported to be formed around ZSM-5 zeolite by dealuminating the outer surface [37], treating ZSM-5 zeolite crystals with silicalite-1 seeds [38] and one-step synthesis in alkaline or fluoride medium [39]. This process turns the material into a core-shell structured zeolite. Moreover, similar materials can be synthesized by seeded growth using mesoporous or conventional ZSM-5 zeolite as the seed 
crystals $[31,32,40,41]$. Unfortunately, these shell growth methods have negative side effects like inducing nucleation of individual silicalite-1 seeds and lack of thickness control of the external silicalite-1 layer which provokes the diffusion limitation and blockage of the pores $[41,42]$.

The aforementioned surface passivation of acidic zeolites has been demonstrated by different groups to enhance the catalytic performance in MTH $[8,35]$. Kustova et al. synthesized a mesoporous ZSM-5 core-shell via a sophisticated method. The catalytic test showed that the novel mesoporous ZSM-5 core-shell performs better than mesoporous ZSM-5 yet it suffers from rapid deactivation due to structural defects [32]. Very recently, Li et al. synthesized a silicalite-1 layer on mesoporous ZSM-5. The material is produced by dissolving a mesoporous ZSM-5 in a mixture of fumed silica and TPAOH under hydrothermal conditions. They tested the catalyst for methanol conversion at atmospheric pressure to demonstrate lifetime improvement [43].

Herein, we focus on a simple solid-state steam-assisted method for creating a non-acidic ultrathin silicalite-1 layer around mesoporous ZSM-5 crystals to address the issue of coke accumulation on the surface of ZSM-5 zeolite during methanol to hydrocarbons transformation. In previous studies, the shell is often grown so that the pores are blocked, which results in reduced accessibility to the active sites in the crystals. Here, we report a new protocol to avoid pore blockage while growing the layer of silicalite-1 on mesoporous ZSM-5. In addition, there is always the possibility of individual nucleation of silicalite-1 via the sol-gel method synthesis, where the ZSM-5 is dissolved in a mixture of silica source and structure directing agent. However, as we will show in this work, our method 
effectively minimizes these risks. The conversion of methanol-to-hydrocarbon (MTH) products such as light olefins, gasoline and aromatics has been the focus of several investigations since the process was patented in 1977 [44-50]. The most stable and active commercial catalyst for methanol-to-gasoline (MTG) process is microporous ZSM-5 with Brønsted acid sites within the confined micropores and on the surface [51]. Based on literature [52-55], it is proposed that in the ZSM-5 zeolites with interconnecting channels, the deactivation initializes through coke formation at the outer rim of the crystallites, which will limit the access to the active sites. As the coke load increases, the access limitation will grow overtime as well. Finally, at high coke content the deactivation scenario is blockage of pore entrance by graphitic compounds, which will cause the accumulation of hydrocarbon compound in the channel intersections and lead to complete limitation of access to active sites. Thus, here the catalytic performances of conventional ZSM-5, mesoporous ZSM-5 and the surface passivated mesoporous ZSM-5 (as illustrated schematically in Figure 1) are tested in the MTH reaction under elevated pressure and temperature condition to study the variation of their catalytic performance.

\section{Experimental}

\subsection{Catalysts preparation}

In this study, three acidic ZSM-5 zeolite with different morphologies were synthesized: a conventional ZSM-5, a carbon template mesoporous ZSM-5 and a mesoporous ZSM-5 with an outer layer of silicalite-1.

\subsubsection{Synthesis of conventional ZSM-5}


Tetrapropylammonium hydroxide (TPAOH, Sigma-Aldrich, $1.0 \mathrm{M}_{\text {in }} \mathrm{H}_{2} \mathrm{O}$ ) and tetraethyl orthosilicate (TEOS, Sigma-Aldrich, $\geq 99.0 \%$ ) were used as the structure directing agent (SDA) and silicon source, respectively, in all of the syntheses. For synthesis of conventional ZSM-5 (Conv-ZSM-5), $0.016 \mathrm{~g}$ of sodium aluminate $\left(\mathrm{NaAlO}_{2}\right.$, SigmaAldrich, anhydrous) was dissolved in $7.2 \mathrm{ml} \mathrm{TPAOH}$. Then $4.4 \mathrm{ml}$ of TEOS was added dropwise to the solution stirring in a Teflon beaker. The mixture was stirred for 1 hour and then heated in a Teflon-lined stainless steel autoclave at $180^{\circ} \mathrm{C}$ for $24 \mathrm{~h}$ under autogenous pressure. The product was separated from the liquid phase by filtration, washed several times with distilled water, dried at $80{ }^{\circ} \mathrm{C}$ overnight and then calcined for $20 \mathrm{~h}$ at $550{ }^{\circ} \mathrm{C}$. Finally, the sample was ion exchanged to the proton form (see 2.1.4 section) and labelled as Conv-ZSM-5 (Figure 1 a)).

\subsubsection{Synthesis of mesoporous ZSM-5}

Mesoporous ZSM-5 zeolite was synthesized using carbon black particles (BP-2000), with average particle diameter of $12 \mathrm{~nm}$, as hard template. First, $0.01 \mathrm{~g}$ of sodium aluminate was dissolved in $7.2 \mathrm{ml}$ TPAOH and then $2 \mathrm{~g}$ of carbon black was impregnated with the solution in a Teflon beaker and dried overnight at room temperature. The dried mixture was impregnated with $4.4 \mathrm{ml}$ of TEOS and dried overnight again at room temperature. Then the beaker was placed in a Teflon-lined stainless steel autoclave and $15 \mathrm{ml}$ of distilled water was added into the autoclave, around the beaker, to produce saturated steam. The autoclave was heated at $180^{\circ} \mathrm{C}$ for $72 \mathrm{~h}$. After the autoclave was quenched, synthesized powder was collected, washed with distilled water, dried at $80{ }^{\circ} \mathrm{C}$ for $24 \mathrm{~h}$ and finally calcined at $550{ }^{\circ} \mathrm{C}$ 
for $20 \mathrm{~h}$. This sample was also ion exchanged to the proton form (see 2.1.4 section) and labelled as Meso-ZSM-5 (Figure $1 \mathrm{~b})$ ).

\subsubsection{Synthesis of silicalite-1 layer}

A layer of silicalite-1 was grown around mesoporous ZSM-5 after pulverizing the assynthesized mesoporous ZSM-5 zeolite in a mortar and drying the powder in vacuum oven over night at $60{ }^{\circ} \mathrm{C}$ to remove the water. $1.0 \mathrm{~g}$ of the zeolite was impregnating with $7.2 \mathrm{ml}$ TPAOH in a Teflon beaker. The mixture was well mixed for 15 minutes and dried overnight at room temperature. Afterwards, the material was impregnated with $4.4 \mathrm{ml}$ TEOS, stirred 3-4 times every hour and dried overnight at room temperature. The beaker was placed in a Teflon-lined stainless steel autoclave and $15 \mathrm{ml}$ of distilled water was added into the autoclave, around the beaker, to produce saturated steam. The autoclave was heated at $180{ }^{\circ} \mathrm{C}$ for $72 \mathrm{~h}$. After the autoclave was quenched, synthesized powder was collected, washed with distilled water, dried at $80{ }^{\circ} \mathrm{C}$ for $24 \mathrm{~h}$ and finally calcined at $550{ }^{\circ} \mathrm{C}$ for $20 \mathrm{~h}$. The final product was ion exchanged (see 2.1.4 section) and labeled as ShellMeso-ZSM-5 (Figure 1 c)).

\subsubsection{Ion exchange}

Prior to catalytic testing, all ZSM-5 samples were ion exchanged by adding $1 \mathrm{~g}$ of zeolite in $80 \mathrm{ml}$ of $1 \mathrm{M}$ ammonium nitrate aqueous solution and stirring the solution at $80{ }^{\circ} \mathrm{C}$ for 1 hour. The process was repeated three times while the last ion exchange was carried out overnight. Afterwards, the solid was separated from the liquid by centrifugation, washed 
with water and dried in the oven for $12 \mathrm{~h}$ at $80{ }^{\circ} \mathrm{C}$. The final solids were calcined at $550{ }^{\circ} \mathrm{C}$ for $10 \mathrm{~h}$ in air to achieve protonated ZSM-5.

\subsection{Characterization procedure}

All of the fresh and spent catalysts were characterized with powder X-ray diffraction at ambient atmosphere and temperature with a Bruker D8-A25 instrument using monochromatic $\mathrm{CuK} \alpha 1$ radiation $(\lambda=1.5406 \AA)$ from a fine-focus sealed tube source and a LynxEye XE position sensitive detector operated in transmission geometry using a 0.5 mm quartz capillary. The patterns were analyzed by Rietveld refinement using TOPAS [56] to extract the unit cell parameters. Elemental analysis was used to determine the exact amount of $\mathrm{Si}$ and $\mathrm{Al}$ in the prepared zeolites. These analysis were carried out using inductively couples plasma optical emission spectroscopy (ICP-OES) in an Agilent 720 ICP-OES spectrometer. X-ray photoelectron spectroscopy (XPS) analysis was performed with a Thermo Scientific K-Alpha X-ray photoelectron spectrometer equipped with a hemispherical analyzer and an $\mathrm{Al} \mathrm{K} \alpha$ micro-focused monochromator. The crystal sizes and morphologies were investigated by scanning electron microscopy (SEM) using a Quanta 200 ESEM FEG operated at $20 \mathrm{kV}$ and by transmission electron microscopy (TEM) on a FEI Tecnai T20 G2 microscope operated at $200 \mathrm{kV}$. $\mathrm{N}_{2}$ physisorption was performed at liquid nitrogen temperature on a Micromeritics 3Flex surface area and porosimetry analyzer. Samples were outgassed under vacuum at $400{ }^{\circ} \mathrm{C}$ overnight prior to measurement. In the case of catalysts obtained from the quenching experiments, the pretreatment was carried out at $200{ }^{\circ} \mathrm{C}$ under vacuum to preserve hydrocarbons retained inside the structure. The specific surface area $\left(\mathrm{S}_{\mathrm{BET}}\right)$ was calculated from the $\mathrm{N}_{2}$ adsorption data by BET method 
in the relative range $\left(\mathrm{P} / \mathrm{P}_{0}\right)$ of $0.05-0.3$. On the other hand, micropore volumes $\left(\mathrm{V}_{\text {micro }}\right)$ and external surface area $\left(S_{\text {ext }}\right.$ were determined by t-plot method using MicroActive software. Finally, the total pore volumes $\left(\mathrm{V}_{\text {total }}\right)$ were calculated from the amount of adsorbed nitrogen at the relative pressure of $\mathrm{P} / \mathrm{P}_{0}=0.95$ (before the onset of interparticle condensation) and pore size distribution is obtained from BJH model using adsorption and desorption branches.

The amount of the acid sites and their distribution were measured by Fourier transformed infrared spectroscopy (FTIR) with a Bruker VERTEX 70v instrument, using pyridine as the basic probe molecule. The measurements were performed in transmission mode on selfsupported wafers, which were mounted in home-made quartz cells. In a typical procedure, the samples were outgassed at $400{ }^{\circ} \mathrm{C}$ overnight under vacuum to remove adsorbed water. After dehydration, the samples were cooled to $150{ }^{\circ} \mathrm{C}$ and exposed to pyridine vapors until complete saturation of the pores. Finally, the samples were outgassed under vacuum at 150 ${ }^{\circ} \mathrm{C}$ for $2 \mathrm{~h}$ to remove the excess physisorbed molecules of pyridine. Spectra were recorded at ambient temperature and have been normalized to the framework vibration in the range of 1950-1760 $\mathrm{min}^{-1}$ in order to compare band intensities for the entire spectra set. Temperature programmed desorption of Ammonia ( $\left.\mathrm{NH}_{3}-\mathrm{TPD}\right)$ was measured on a Mettler Toledo TGA-DSC1. Prior to adding ammonia, the samples were heated to $500{ }^{\circ} \mathrm{C}$ in a mix flow of He and Ar then cooled down to $150{ }^{\circ} \mathrm{C}$. Then ammonia with the concentration of 2 $\%$ in inert gases was introduced for $30 \mathrm{~min}$ at $150{ }^{\circ} \mathrm{C}$ followed by flushing with pure inert gases for 3 hours to remove excess ammonia. Finally, the ammonia desorption was implemented by elevating the temperature to $500{ }^{\circ} \mathrm{C}$ with a heating ramp of $5{ }^{\circ} \mathrm{C} \mathrm{min}^{-1}$. 
The amount of coke deposited was quantified by thermo-gravimetric analysis (TGA) on a Netzsch STA 449 F3- Jupiter equipment. The catalysts were heated at a rate of $5{ }^{\circ} \mathrm{C} \mathrm{min}{ }^{-1}$ in synthetic air to $900{ }^{\circ} \mathrm{C}$. Soluble coke species trapped in the pores of zeolite catalysts were analyzed by following the Guisnet method [57]. Approximately, $15 \mathrm{mg}$ of the used catalyst was transferred into a Teflon vial with $1 \mathrm{ml}$ of hydrofluoric acid (15\%) to dissolve the top layers of zeolite in order to release the organic species. Then the organic molecules were extracted from the solution by adding $1 \mathrm{ml}$ of dichloromethane with ortho-chlorotoluene as internal standard. The extracted soluble coke was then analyzed by GC-MS (Agilent $7890 \mathrm{GC}$ with 5975 MSD) equipped with a J\&W DB-5ms column (60 m, $0.25 \mathrm{~mm}$ i.d. and film thickness of $0.25 \mu \mathrm{m})$. The NIST98 database was used for identification of the compounds.

\subsection{Methanol to hydrocarbons reaction}

Catalytic testing experiments were carried out in a fixed bed stainless steel reactor with inner diameter of $6 \mathrm{~mm}$ (PID Eng\&Tech, Microactivity Effi reactor). A thermocouple was placed inside the reactor in contact with the top section of the catalyst bed to monitor the temperature of the reaction. Catalyst powder was pressed, gently crushed and sieved to fraction sizes of $250-420 \mu \mathrm{m}$ in order to avoid pressure build-up. Catalytic tests were performed at the pressure of 5 barg and temperature of $400{ }^{\circ} \mathrm{C}$ using $210 \mathrm{mg}$ of the fractionated catalyst. For each test, catalysts were pretreated in the reactor at $550{ }^{\circ} \mathrm{C}$ for $1 \mathrm{~h}$ in $100 \mathrm{Nml} \mathrm{min}^{-1} \mathrm{~N}_{2}$ flow. Then, catalysts were calcined under pure oxygen flow to remove adsorbed water and hydrocarbons. The temperature was lowered to the reaction temperature and the $\mathrm{N}_{2}$ flow (102 $\mathrm{NmL} \mathrm{min}^{-1}$ ), as the carrier gas, was flown through a heated evaporator 
to feed the methanol (10 mol\% in $\mathrm{N}_{2}$ ) into the reactor corresponding to weight hourly space velocity (WHSV) of $4.7 \mathrm{~g}_{\mathrm{MeOH}} \mathrm{g}_{\mathrm{cat}}{ }^{-1} \mathrm{~h}^{-1}$. The outlet effluent stream was analyzed by online GC analysis with an Agilent 6890A equipped with a DB-5 (60 m x $0.55 \mathrm{~mm}, 3 \mu \mathrm{m}$ column) by J\&W Scientific.

\section{Results and discussion}

\subsection{Characterization of the catalysts}

The powder XRD patterns of the Conv-ZSM-5, Meso-ZSM-5 and Shell-Meso-ZSM-5 are shown in Figure 2. All synthesized samples are highly crystalline frameworks without impurities, having the MFI topology.

Nitrogen physisorption provides textural properties of the synthesized samples. As it can be observed in Figure 3, all samples show a relatively steep nitrogen uptake at partial pressures up to $\mathrm{P} / \mathrm{P}_{0}=0.01$, which is an indication of the presence of micropores in MFI zeolite frameworks. Conv-ZSM-5 has a typical type I isotherm (according to IUPAC classification) [58], which is characteristic of microporous materials. The small hysteresis loops at around $\mathrm{P} / \mathrm{P}_{0}=0.15$ is due to phase transition of $\mathrm{N}_{2}$ in MFI micropores [59]. Furthermore, the isotherm for the Meso-ZSM-5 is type IV however, it contains a hysteresis loop of type $\mathrm{H} 1$ at relative pressure higher than $\mathrm{P} / \mathrm{P}_{0}=0.8$ that shows the presence of uniform mesopores with narrow size distribution [58,60,61]. Shell-Meso-ZSM-5 sample also shows a type IV isotherm but with hysteresis loop of type H2(a) closing sharply at relative pressure of 0.45 , which is found in more complex pore structure. This type of hysteresis loop is formed due to a physical phenomenon known as TSE (tensile strength 
effect), suggesting an inkbottle pore system where hollow voids inside the crystal are connected to outside through smaller pores $[62,63]$. Individual physisorption isotherms of each zeolite sample can be found in supporting information Figure S1. The BJH analysis of the desorption isotherm for the pore size distribution (PSD) (Figure S2) shows a narrow peak appearing at around $4 \mathrm{~nm}$ for Shell-Meso-ZSM-5 zeolite, which does not necessarily suggest physical uniform mesopores since the calculated pore size distribution from the adsorption branch shows no pores in that range. Therefore, this implies that appearance of this peak around $4 \mathrm{~nm}$ is caused by TSE phenomenon and not physical mesopores. In addition, PSD results obtained from adsorption branch of Shell-Meso-ZSM-5 show the presence of mesopores in the sample while these pores are almost absent in PSD of desorption branch due to accessibility of mesopores via micropores during the evacuation of $\mathrm{N}_{2}$.

BET surface area, micro and mesoporous volumes of the samples are presented in Table 1. As expected, Meso-ZSM-5 has higher surface area as well as higher total pore volume in comparison with conventional microporous zeolite (Conv-ZSM-5). In the Shell-MesoZSM-5, the surface area does not change but the total pore volume increases slightly by $14 \%$ in comparison with Meso-ZSM-5. With the obtained data, we can speculate that the encapsulation of some of external voids during the shell formation and partial dissolution of poorly crystalline and defects by structure directing agent (TPAOH) may conjointly cause the increase in total pore volume.

Figure 4 shows SEM images of the Conv-ZSM-5, Meso-ZSM-5 and Shell-Meso-ZSM-5 after ion exchange and calcination. These representative images confirm that all three 
zeolite samples are highly crystalline, which is in good agreement with the XRD results. Furthermore, sizes of crystals are rather uniform for each sample. The average crystal size of conventional zeolite (Conv-ZSM-5) with the typical shape of MFI-type crystals is determined from SEM images in Figure 4 to be about $250 \mathrm{~nm}$. As it is observed in SEM (Figure 4) and TEM images (Figure 5), Meso-ZSM-5 and Shell-Meso-ZSM-5 zeolites have an average particle size range between $1000-2000 \mathrm{~nm}$. In addition, the obvious difference between the surfaces of Meso-ZSM-5 and Shell-Meso-ZSM-5 crystals could be the result of the shell formation. TEM images complement the same observation clearly. From TEM images in Figure 5, it is possible to see the silicalite-1 shell grown around the mesoporous zeolite crystal, which has resulted in a more defined shape and polished surface of ShellMeso-ZSM-5 compared to the rough Meso-ZSM-5 sample. The ultrathin layer of silicalite1 is estimated from the TEM images to be approximately $15 \mathrm{~nm}$ (marked in Figure 5d).

XPS confirms the high degree of surface coverage with the silicalite-1. Figure 6 shows the XPS analysis results for mesoporous ZSM-5 and mesoporous core ZSM-5 covered by silicalite-1 shell in the Al 2p binding energy range. The XPS spectra of mesoporous ZSM-5 zeolite show one peak at $76.67 \mathrm{eV}$, as expected, indicating the presence of $\mathrm{Al}$. A weak negligible peak, which is mostly noise rather than a signal, also appears in the spectrum of mesoporous ZSM-5 zeolite covered by silicalite-1. It is noteworthy that XPS is a surface sensitive analysis and the weaker intensity indicates that the signals are collected from the elements that are situated in the inner layer of the zeolite. Also, the penetration depth of the analysis is in the range of the silicalite- 1 thickness. Thus, the small Al signal for the ShellMeso-ZSM-5 is likely to be collected from the inner layer or not fully covered ZSM-5 core. 
The chemical compositions of the zeolites are determined by ICP-OES, as presented in Table 2, the ratio between silicon to aluminum ( $\mathrm{Si} / \mathrm{Al})$ is 140,150 and 163 for Conv-ZSM5, Meso-ZSM-5 and Shell-Meso-ZSM-5, respectively. Si/Al ratio for Shell-Meso-ZSM-5 increases compared to Meso-ZSM-5 as the result of silicalite-1 formation around the ZSM5 crystals. The shell thickness calculation based on TEM observation and weight increase of the sample after shell growth, also confirm a Si/Al ratio of 154-160 for Shell-MesoZSM-5, which is in acceptable agreement with the ICP-OES result.

The amount of acid sites and their nature (Brønsted or Lewis type) are determined by pyridine IR. The spectra of the activated zeolites in the hydroxyl group stretching region (3800-3400 $\mathrm{cm}^{-1}$ ) are shown in Figure 7. Bands at $3610 \mathrm{~cm}^{-1}$ (ascribed to Brønsted sites) and at $3645 \mathrm{~cm}^{-1}$ (attributed to external silanol groups) are observed for all samples. The intensity of the band assigned to external silanols is higher for the Meso-ZSM-5 and the Shell-Meso-ZSM-5 compared to the Conv-ZSM-5, which is in agreement with the higher external surface area (including the mesopores surface area) for the samples. The minor increase in the intensity of the external silanols for the Shell-Meso-ZSM-5 compared to the Meso-ZSM-5 might be related to extra layer of silicalite-1 in the sample. In addition, a very small band around $3728 \mathrm{~cm}^{-1}$ is related to internal silanol groups [64] and seems to be relatively more abundant in the Conv-ZSM-5 compared to the other samples. Finally, the band at $3670 \mathrm{~cm}^{-1}$, which is typically assigned to hydroxyl groups attached to partially extra-framework aluminum [51] is also detected for all samples but slightly more pronounced in the Meso-ZSM-5 and Shell-Meso-ZSM-5. This higher framework distortion 
is caused under synthesis conditions of the mesoporous ZSM-5 using carbon black particles [27].

The spectra corresponding to the ring vibrational modes of the pyridine molecule is also showed in Figure 7 after pyridine chemisorption. Upon pyridine adsorption, the bands at the region $3700-3550 \mathrm{~cm}^{-1}$ are completely removed in all samples. However, the bands in $3780-3700 \mathrm{~cm}^{-1}$ are still present but have lower intensities (Figure 7). The observed reduction is due to acidic nature of these hydroxyl groups, which interact with the pyridine. The two characteristic bands at the frequencies of 1545 and $1450 \mathrm{~cm}^{-1}$ are assigned to adsorbed pyridine molecules on Brønsted (BA) and Lewis (LA) acid sites, respectively $[64,65]$. The total amount of acid sites is calculated from the spectra by integrating the area of these two bands (Table 2). Furthermore, the band at $1500 \mathrm{~cm}^{-1}$ is assigned to the combination of both Brønsted and Lewis acid sites. It is clear that Conv-ZSM-5 has a higher density of Brønsted acid sites compared to the mesoporous sample, which is consistent with the previous results obtained by Kustova et. al. using $\mathrm{NH}_{3}$-TPD for measuring the acid sites [32]. Nonetheless, there is a small decrease in the density of acid sites when the silicalite- 1 shell is incorporated, which is an indication of the presence of non-acidic material. The fact that the decrease is small shows that the layer is indeed quite thin, which is consistent with the observed thickness of $15 \mathrm{~nm}$ for the shell in TEM microscopy.

The measurements of acid site densities performed by temperature programmed desorption (TPD) of ammonia confirm the same results obtained from pyridine IR for the strong acid site distribution (Table 3). Conv-ZSM-5 and Meso-ZSM-5 have higher density of strong 
acid sites, while the Shell-Meso-ZSM-5 zeolite has less Brønsted acid sites. This is predictable due to the additional amount of silicalite-1 in the Shell-Meso-ZSM-5 sample that reduces the concentration of strong acid sites per gram of the catalyst. The ammonia TPD profiles (Figure 8) show a slight decrease in ammonia at high temperature above $300^{\circ} \mathrm{C}$ for Shell-Meso-ZSM-5 compared to Conv-ZSM-5 and Meso-ZSM-5, as expected. For the Conv-ZSM-5 product, the ammonia desorption is lower at temperatures below $300^{\circ} \mathrm{C}$ indicating a lower concentration of weak acid sites, which is in good agreement with the measured Lewis acid sites from pyridine IR (Table 2). In addition, the calculated Si/Al ratios from the ammonia uptake for Conv-ZSM-5 and Meso-ZSM-5 samples are in reasonable agreement with the results obtained from ICP-OES considering the uncertainty of ammonia TPD analysis.

\subsection{Catalytic performance}

The catalytic performance of the different ZSM-5 catalysts (Conv-ZSM-5, Meso-ZSM-5 and Shell-Meso-ZSM-5) is presented in Figure 9 for conversion of methanol to hydrocarbons as a function of time on stream (TOS) for WHSV $=4.7 \mathrm{~g}_{\mathrm{MeOH}} \mathrm{g}_{\mathrm{cat}}{ }^{-1} \mathrm{~h}^{-1}$.

All of the ZSM-5 catalysts show full conversion initially for the WHSV=4.7 $\mathrm{g}_{\mathrm{MeOH}} \mathrm{g}_{\mathrm{cat}}{ }^{-1}$ $\mathrm{h}^{-1}$. However, the lifetime and deactivation trend are substantially different among the samples as the reaction proceeds. The lifetime of a ZSM-5 catalyst varies depending on certain sample characteristics such as density of acid sites, crystal size and presence of defects among others [64]. For the Conv-ZSM-5, the lifetime is nearly 7 hours until complete deactivation at the WHSV of $4.7 \mathrm{~g}_{\mathrm{MeOH}} \mathrm{g}_{\mathrm{cat}}{ }^{-1} \mathrm{~h}^{-1}$. Moreover, the deactivation is 
rather fast and sudden compared to the other two catalysts. The main reason for the deactivation is postulated to be the blockage of the pore openings on the external surface and internal pore intersections. The Meso-ZSM-5 shows longer lifetime and better stability with slow deactivation. After the initial full conversion of methanol, the catalyst starts to deactivate with a less steep trend and slower than Conv-ZSM-5. This specific catalyst remains active for 45 hours until it reaches $20 \%$ activity and it retains at same conversion level for a few hours before the catalyst was quenched. Despite the larger particle size of Meso-ZSM-5 (2000nm) compared to Conv-ZSM-5 (250nm), the enhanced performance agrees with the alleviation of the diffusion limitation due to presence of mesoporosity. Hence, catalysts prepared by introducing mesoporosity (Meso-ZSM-5) show longer lifetime and perform better than conventional ZSM-5 (Conv-ZSM-5) as they did in the previously reported studies $[20,32,66]$.

Also, Shell-Meso-ZSM-5 exhibits a significant improvement in the lifetime as it deactivates more slowly than Meso-ZSM-5. The full conversion lasts shorter as compared to Meso-ZSM-5, and that can be caused by the lower concentration of Brønsted acid sites, as measured by Pyridine IR and $\mathrm{NH}_{3}$-TPD. The lifetime of the core-shell zeolite seems to be more than 70 hours and it remained at $40 \%$ conversion longer than shown in Figure 9 , at which point the sample was quenched. The deactivation is delayed, presumably due to passivation of the acid sites on the external surface of mesoporous zeolite. Additionally, products yield of MTH conversion over different catalysts are listed in Table S1 at 100\% conversion. Results show that the product yields of $\mathrm{C}_{1}$ and $\mathrm{C}_{3}$ increase while that of $\mathrm{C}_{6+}$ 
decreases for Shell-Meso-ZSM-5 compared to Meso-ZSM-5, which can be attributed to the silicalite- 1 shell.

In this process, coke can be originated from either the reactants, products or a combination of both. This leads to three different deactivation trends depending on the origin of the coke [67]. The deactivation curve for Conv-ZSM-5 zeolite has the typical inverse $S$ shape with sudden deactivation and methanol break-through [68] indicating that the deactivation species are originated mainly from the methanol. Shell-Meso-ZSM-5 catalyst shows a deactivation curve with a gradually decreasing slope over time while the product concentration decreases. Therefore, it is likely that mainly the product is contributing to coke formation. However, deactivation trend for Meso-ZSM-5 that shows intermediate behavior, may imply that coke deposition is caused by both methanol and product.

Cumulative conversion capacities for all catalysts are calculated based on conversion of methanol until $50 \%$ deactivation of catalysts. Moreover, the amount of Brønsted acid sites obtained from pyridine IR has been taken into consideration, to quantify how is the conversion per acid site and the resistance of the zeolites to deactivation. In this sense, the conversion capacity is defined as mol of methanol converted per mmol of Brønsted acid sites. The obtained total amount of converted methanol is in good agreement with our observation of lifetime for the corresponding catalysts in this work. The Shell-Meso-ZSM5 has the highest conversion capacity (almost two times higher than Meso-ZSM-5), while Conv-ZSM-5 has the lowest. 


\subsection{Retained coke}

Aiming to study the organic materials retained within the pores after certain time on stream, all catalysts are quenched and then studied by different means. Figure 11 shows mass loss versus temperature for the deactivated Conv-ZSM-5, Meso-ZSM-5 and ShellMeso-ZSM-5 after 16, 45 and 70 hours on stream, respectively. TGA shows that the carbon content of Meso-ZSM-5 ( $\square 8.2 \mathrm{wt} \%$ ) is higher than Shell-Meso-ZSM-5 ( $\square 7 \mathrm{wt} \%$ ) even though the Shell-Meso-ZSM-5 catalyst has been on the stream for a longer time (70 hours). The conv-ZSM-5 with the highest Brønsted acid site density and the shortest lifetime among these three catalysts has the least coke content around $5 \mathrm{wt} \%$. The Conv-ZSM-5 catalyst deactivates fast and TGA results show a small weight loss. Based on previous study on conventional ZSM-5, it is likely that the aromatic products deposit on the outer rim of the crystal and external surface, while diffusing out of micropores, to form external coke. This external coke continues to grow without spatial restriction at high thermal condition and form graphite-like compounds to eventually block the pore openings on the surface $[69,70]$. Furthermore, the different colors of the deactivated catalysts would suggest that there are different coke species deposited in different locations of crystals (supporting information Figure S3). In addition, textural properties of the used catalysts obtained from $\mathrm{N}_{2}$ physisorption show that total pore volume has decreased in all three catalysts because of the occupation of the micropores by the coke species. Fresh MesoZSM-5 and Shell-Meso-ZSM-5 catalysts had the same BET surface area but it has reduced more in the Meso-ZSM-5 after deactivation (supporting information Table S2). 
The chromatograms of the detected soluble species are shown in Figure 12.

Polymethylated benzene (1-6 methyl groups) species are the main compounds retained in all zeolite samples as reported in previous studies as well [71-73]. As it can be seen, larger amounts of heavier compounds such as poly-methyl-benzenes, naphthalene and anthracene derivatives, are identified in the Conv-ZSM-5. In addition, small hydrocarbon compounds such as toluene and xylenes are found in Conv-ZSM-5 while there is a small amount of xylene detected in Meso-ZSM-5 and Shell-Meso-ZSM-5 samples. Moreover, both MesoZSM-5 and Shell-Meso-ZSM-5 show similar chromatograms with similar total areas. However, different weight losses obtained from TGA implies that Meso-ZSM-5 with more weight loss contained more non-soluble coke species than Shell-Meso-ZSM-5 catalyst. This suggests that lower conversion capacity of Meso-ZSM-5 can be a result of a higher degree of deactivation by non-soluble coke.

The spent catalysts tested at WHSV $=4.7 \mathrm{~g}_{\mathrm{MeOH}} \mathrm{g}_{\mathrm{cat}}{ }^{-1} \mathrm{~h}^{-1}$ were further analyzed by X-ray diffraction (Figure 13). XRD reveals that small but clear structural changes are induced in the frameworks during the MTH reaction. Table 4 shows the unit cell dimensions and cell volume of the samples before and after the catalytic testing as extracted from the Rietveld refinements. We have previously demonstrated that the difference in length of the $a$ - and $b$ vectors is a straightforward descriptor that carries the essential information regarding the degree of deactivation of a ZSM-5 catalyst. Internal coking typically leads to a distortion of the zeolite unit cell, as also demonstrated for SAPO-34 [74] and ZSM-22 [75]. In the case of ZSM-5, DFT calculations have confirmed that an increased concentration of methylbenzene molecules located in the channel intersections leads to a gradual shorting of the $a$-vector and a lengthening of the $b$-vector. Thus, the difference between the two 
vectors, the $a$ minus $b$ parameter, will gradually become smaller as the catalyst is increasingly deactivated $[73,76]$.

Initially, the fresh catalysts have almost identical values for the $a$ minus $b$ parameter, despite the insertion of mesopores and the coating with silicalite-1 (Table 4). After reaction, however, a different picture emerges. For the Conv-ZSM-5 and the Meso-ZSM-5, the values have decreased by close to $0.07 \AA$, whereas for the Shell-Meso-ZSM-5, the $a$ minus $b$ parameter has decreased substantially less, by only $0.033 \AA$. This could indicate a lesser degree of deactivation (see conversion data in Figure 9), but might also be attributed to an averaging effect. We expect no coke formation, and thus no change in the unit cell for the silicalite-1 layer. As XRD is a bulk technique, one could therefore expect that the XRD analysis is an average of fresh (silicalite-1 coating layer) and deactivated (inner ZSM-5 core) catalyst. However, keeping in mind that the silicalite-1 layer is very thin, it appears more plausible to attribute the modest change in the $a$ minus $b$ parameter to a smaller amount of internal coke and lesser degree of deactivation. It should also be kept in mind that the final end-value of the $a$ minus $b$ parameter for a fully deactivated ZSM-5 catalyst is sample dependent [73]. However, the Meso-ZSM-5 and Shell-Meso-ZSM-5 are derived by the same parent sample and consequently should share the same internal network.

Even so, it is clear that despite the longer exposure to catalytic testing conditions for the Shell-Meso-ZSM-5, the coke deposited has induced the least structural changes in the internal framework of the material. Another small point worth pointing out, is that the data presented in Table 4 demonstrate that the $a$ minus $b$ parameter is a useful deactivation descriptor also for mesoporous (and coated) ZSM-5 catalysts. 
In brief, it is clear from the XRD that samples are highly crystalline and no other phases other than MFI are formed (Figure 2). The decrease in the aluminum content evidences the presence of a silica phase in the sample Shell-Meso-ZSM-5 (Table 2). Moreover, TEM pictures reveal the formation of thin layer. On the other hand, comparing $\mathrm{N}_{2}$ physisorption isotherms of Meso-ZSM-5 and Shell-Meso-ZSM-5, it is possible to hypothesize that the cylindrical pores formed in the mesoporous sample are accessible through the microporous shell in the Shell-Meso-ZMS-5 sample. These observations are also supported by the disappearance of the band corresponding to aluminum in the XPS analysis. Finally, the small negligible signal suggests that the shell is indeed rather thin, which is also supported by the small decrease in the density of Brønsted acid sites registered by pyridine FTIR. Rietveld refinements on long exposure XRD patterns demonstrated that the core shell modification substantially improved the catalyst lifetime while the deposited coke had the least impact on structural changes of internal framework. In summary, combining all these techniques we were able to prove the presence of a thin layer of silicalite- 1 around the mesoporous ZSM-5 crystals and significantly improve the catalytic properties of the modified mesoporous ZSM-5 catalyst. As it was reported by Li. et al. coating mesoporous ZSM-5 with thin layer of silicalit-1 enhances the catalytic performance of catalyst for MTH conversion at atmospheric pressure and $370{ }^{\circ} \mathrm{C}$ [43]. The synthesis approach we proposed here is free of individual nucleation of silicalite-1 crystals while achieving an ultrathin layer. Furthermore, the catalyst was tested in much more harsh conditions at 5 barg and 400 ${ }^{\circ} \mathrm{C}$ and showed outstanding performance. 


\section{Conclusion}

We have shown an efficient and simple approach to grow a non-acidic shell around acidic mesoporous ZSM-5 zeolite. In the developed material, the exterior surface of each ZSM-5 crystal is covered with a nano-metric thin layer of silicalite-1, without the presence of individual silicalite-1 crystals. Catalytic results of methanol conversion under elevated pressure and temperature conditions indicate that the lifetime of the mesoporous ZSM-5 with silicalite-1 layer is significantly improved in comparison to the unmodified ZSM-5 zeolite. Thus, the developed synthesis approach of ultrathin shell for surface passivation of acidic zeolites can be viewed as a general method to design novel surface-modified materials. Importantly, the studied modification opens opportunities for utilization of full conversion capacity in zeolite crystal and prolong their catalytic lifetime, which is greatly needed in various industries.

\section{Acknowledgement}

The authors are grateful for funding from the Independent Research Fund Denmark (grant no. 6111-00237), from Villum fonden (Grant No. 13158), and from Haldor Topsøe A/S. The authors acknowledge access to catalysis section at University of Oslo. Finally, we acknowledge Aino Nielsen for the help with FTIR analysis.

\section{Appendix A.}

Supplementary data 


\section{References}

[1] J.K. Francis, E. Higgins, Permanent peripheral neuropathy: A case report on a rare but serious debilitating side-effect of fluoroquinolone administration, J. Investig. Med. High Impact Case Reports. 2 (2014) 175-188. doi:10.1177/2324709614545225.

[2] I. Fechete, Y. Wang, J.C. Védrine, The past, present and future of heterogeneous catalysis, Catal. Today. 189 (2012) 2-27. doi:10.1016/j.cattod.2012.04.003.

[3] J. Čejka, G. Centi, J. Perez-Pariente, W.J. Roth, Zeolite-based materials for novel catalytic applications: Opportunities, perspectives and open problems, Catal. Today. 179 (2012) 2-15. doi:10.1016/j.cattod.2011.10.006.

[4] A.B. Laursen, K.T. Højholt, L.F. Lundegaard, S.B. Simonsen, S. Helveg, F. Schüth, M. Paul, J.D. Grunwaldt, S. Kegnœes, C.H. Christensen, K. Egeblad, Substrate sizeselective catalysis with zeolite-encapsulated gold nanoparticles, Angew. Chemie Int. Ed. 49 (2010) 3504-3507. doi:10.1002/anie.200906977.

[5] D.H. Olson, G.T. Kokotailo, S.L. Lawton, W.M. Meier, Crystal structure and structure-related properties of ZSM-5, J. Phys. Chem. 85 (1981) 2238-2243. doi:10.1021/j150615a020.

[6] C.D. Chang, The New Zealand Gas-to-Gasoline plant: An engineering tour de force, Catal. Today. 13 (1992) 103-111. doi:10.1016/0920-5861(92)80190-X.

[7] G. Vayssilov, M. Yankov, A. Hamid, Para-selective alkylation of toluene with 
methanol over ZSM-5 zeolites. A kinetic model, Appl. Catal. A, Gen. 94 (1993) 117-130. doi:10.1016/0926-860X(93)85002-7.

[8] F. Cejka, J. Corma, A. Schueth, Introduction to Zeolite Molecular, Elsevier Science, 2007.

[9] J.O. Abildstrøm, M. Kegnæs, G. Hytoft, J. Mielby, S. Kegnæs, Synthesis of mesoporous zeolite catalysts by in situ formation of carbon template over nickel nanoparticles, Microporous Mesoporous Mater. 225 (2016) 232-237. doi:10.1016/j.micromeso.2015.12.015.

[10] A.T. Aguayo, A.G. Gayubo, J.M. Ortega, M. Olazar, J. Bilbao, Catalyst deactivation by coking in the MTG process in fixed and fluidized bed reactors, Catal. Today. 37 (1997) 239-248. doi:10.1016/S0920-5861(97)00015-1.

[11] K.Y. Lee, M.Y. Kang, S.K. Ihm, Deactivation by coke deposition on the HZSM-5 catalysts in the methanol-to-hydrocarbon conversion, J. Phys. Chem. Solids. 73 (2012) 1542-1545. doi:10.1016/j.jpcs.2012.09.005.

[12] S. Van Donk, A.H. Janssen, J.H. Bitter, K.P. De Jong, Generation, characterization, and impact of mesopores in zeolite catalysts, Catal. Rev. - Sci. Eng. 45 (2003) 297319. doi:10.1081/CR-120023908.

[13] J.C. Groen, L.A.A. Peffer, J.A. Moulijn, J. Pérez-Ramírez, Mesoporosity development in ZSM-5 zeolite upon optimized desilication conditions in alkaline medium, Colloids Surfaces A Physicochem. Eng. Asp. 241 (2004) 53-58. 
doi:10.1016/j.colsurfa.2004.04.012.

[14] B. Vogel, C. Schneider, E. Klemm, The synthesis of cresol from toluene and N2O on H[Al]ZSM-5: Minimizing the product diffusion limitation by the use of small crystals, Catal. Letters. 79 (2002) 107-112. doi:10.1023/A:1015392217345.

[15] M. Hartmann, Hierarchical zeolites: A proven strategy to combine shape selectivity with efficient mass transport, Angew. Chemie - Int. Ed. 43 (2004) 5880-5882. doi:10.1002/anie.200460644.

[16] K. Zhang, M.L. Ostraat, Innovations in hierarchical zeolite synthesis, Catal. Today. 264 (2016) 3-15. doi:10.1016/j.cattod.2015.08.012.

[17] E. Koohsaryan, M. Anbia, Nanosized and hierarchical zeolites: A short review, Cuihua Xuebao/Chinese J. Catal. 37 (2016) 447-467. doi:10.1016/S18722067(15)61038-5.

[18] Y. Ni, A. Sun, X. Wu, G. Hai, J. Hu, T. Li, G. Li, The preparation of nano-sized $\mathrm{H}[\mathrm{Zn}, \mathrm{Al}] \mathrm{ZSM}-5$ zeolite and its application in the aromatization of methanol, Microporous Mesoporous Mater. 143 (2011) 435-442. doi:10.1016/j.micromeso.2011.03.029.

[19] S. Van Donk, A.H. Janssen, J.H. Bitter, K.P. De Jong, Generation, characterization, and impact of mesopores in zeolite catalysts, Catal. Rev. - Sci. Eng. 45 (2003) 297319. doi:10.1081/CR-120023908.

[20] J. Kim, M. Choi, R. Ryoo, Effect of mesoporosity against the deactivation of MFI 
zeolite catalyst during the methanol-to-hydrocarbon conversion process, J. Catal. 269 (2010) 219-228. doi:10.1016/j.jcat.2009.11.009.

[21] I. Yarulina, F. Kapteijn, J. Gascon, The importance of heat effects in the methanol to hydrocarbons reaction over ZSM-5: On the role of mesoporosity on catalyst performance, Catal. Sci. Technol. 6 (2016) 5320-5325. doi:10.1039/c6cy00654j.

[22] K. Egeblad, Mesoporous zeolite and zeotype single crystals synthesized in.pdf, Int. Symp. Zeolites Microporous Cryst. (2006). https://findit.dtu.dk/en/catalog/2389431450 (accessed June 20, 2019).

[23] M. Ogura, S. Shinomiya, J. Tateno, Y. Nara, M. Nomura, E. Kikuchi, M. Matsukata, Alkali-treatment technique — new method for modification of structural and acidcatalytic properties of ZSM-5 zeolites, Appl. Catal. A Gen. 219 (2001) 33-43. doi:10.1016/S0926-860X(01)00645-7.

[24] J.C. Groen, J.A. Moulijn, J. Pérez-Ramírez, Decoupling mesoporosity formation and acidity modification in ZSM-5 zeolites by sequential desilication-dealumination, Microporous Mesoporous Mater. 87 (2005) 153-161. doi:10.1016/j.micromeso.2005.07.050.

[25] M. Ogura, S. Shinomiya, J. Tateno, Y. Nara, E. Kikuchi, M. Matsukata, Formation of Uniform Mesopores in ZSM-5 Zeolite through Treatment in Alkaline Solution, Chem. Lett. 29 (2000) 882-883. doi:10.1246/cl.2000.882.

[26] C.J.H. Jacobsen, C. Madsen, J. Houzvicka, I. Schmidt, A. Carlsson, Mesoporous 
zeolite single crystals [2], J. Am. Chem. Soc. 122 (2000) 7116-7117. doi:10.1021/ja000744c.

[27] Z. Pavlačková, G. Košová, N. silková, A. Zukal, J. Čejka, Formation of mesopores in ZSM-5 by carbon templating, Stud. Surf. Sci. Catal. 162 (2006) 905-912. doi:10.1016/S0167-2991(06)80996-1.

[28] H. Chen, M. Yang, W. Shang, Y. Tong, B. Liu, X. Han, J. Zhang, Q. Hao, M. Sun, X. Ma, Organosilane Surfactant-Directed Synthesis of Hierarchical ZSM-5 Zeolites with Improved Catalytic Performance in Methanol-to-Propylene Reaction, Ind. Eng. Chem. Res. 57 (2018) 10956-10966. doi:10.1021/acs.iecr.8b00849.

[29] J.O. Abildstrøm, Z.N. Ali, U.V. Mentzel, J. Mielby, S. Kegnæs, M. Kegnæs, Mesoporous MEL, BEA, and FAU zeolite crystals obtained by: In situ formation of carbon template over metal nanoparticles, New J. Chem. 40 (2016) 4223-4227. doi:10.1039/c5nj02809d.

[30] J. Mielby, J.O. Abildstrøm, F. Wang, T. Kasama, C. Weidenthaler, S. Kegnæs, Oxidation of bioethanol using zeolite-encapsulated gold nanoparticles, Angew. Chemie - Int. Ed. 53 (2014) 12513-12516. doi:10.1002/anie.201406354.

[31] C. Peng, Z. Liu, Y. Yonezawa, Y. Yanaba, N. Katada, I. Murayama, S. Segoshi, T. Okubo, T. Wakihara, Ultrafast post-synthesis treatment to prepare ZSM5 @ Silicalite-1 as a core-shell structured zeolite catalyst, Microporous Mesoporous Mater. 277 (2019) 197-202. doi:10.1016/j.micromeso.2018.10.036. 
[32] M. Kustova, M.S. Holm, C.H. Christensen, Y.H. Pan, P. Beato, T.V.W. Janssens, F. Joensen, J. Nerlov, Synthesis and characterization of mesoporous ZSM-5 core-shell particles for improved catalytic properties, Stud. Surf. Sci. Catal. 174 (2008) 117122. doi:10.1016/S0167-2991(08)80161-9.

[33] D. Mores, E. Stavitski, S.P. Verkleij, A. Lombard, A. Cabiac, L. Rouleau, J. Patarin, A. Simon-Masseron, B.M. Weckhuysen, Core-shell H-ZSM-5/silicalite-1 composites: Brønsted acidity and catalyst deactivation at the individual particle level, Phys. Chem. Chem. Phys. 13 (2011) 15985-15994. doi:10.1039/c1cp21324e.

[34] K. Miyake, Y. Hirota, K. Ono, Y. Uchida, S. Tanaka, N. Nishiyama, Direct and selective conversion of methanol to para-xylene over Zn ion doped ZSM-5/silicalite1 core-shell zeolite catalyst, J. Catal. 342 (2016) 63-66. doi:10.1016/j.jcat.2016.07.008.

[35] J. Zheng, X. Sun, Y. Du, B. Qin, Y. Zhang, H. Zhang, M. Pan, R. Li, Structural features of core-shell zeolite-zeolite composite and its performance for methanol conversion into gasoline and diesel, J. Mater. Res. 31 (2016) 2302-2316. doi:10.1557/jmr.2016.208.

[36] X. Li, F. Rezaei, D.K. Ludlow, A.A. Rownaghi, Synthesis of SAPO-34@ZSM-5 and SAPO-34@Silicalite-1 Core-Shell Zeolite Composites for Ethanol Dehydration, Ind. Eng. Chem. Res. 57 (2018) 1446-1453. doi:10.1021/acs.iecr.7b05075.

[37] L.D. Rollman, ZSM-5 containing aluminum-free shells on its surface, US 4088605, 1978. 
[38] Q. Li, Z. Wang, J. Hedlund, D. Creaser, H. Zhang, X. Zou, A.J. Bons, Synthesis and characterization of colloidal zoned MFI crystals, Microporous Mesoporous Mater. 78 (2005) 1-10. doi:10.1016/j.micromeso.2004.09.010.

[39] A. Lombard, A. Simon-Masseron, L. Rouleau, A. Cabiac, J. Patarin, Synthesis and characterization of core/shell Al-ZSM-5/silicalite-1 zeolite composites prepared in one step, Microporous Mesoporous Mater. 129 (2010) 220-227. doi:10.1016/j.micromeso.2009.09.018.

[40] Y.Q. Deng, W.F. Zhou, H.M. Lv, Y.Y. Zhang, C.T. Au, S.F. Yin, Synthesis of HZSM-5@ silicalite-1 core-shell composite and its catalytic application in the generation of p-xylene by methylation of toluene with methyl bromide, RSC Adv. 4 (2014) 37296-37301. doi:10.1039/c4ra04126g.

[41] A. Ghorbanpour, A. Gumidyala, L.C. Grabow, S.P. Crossley, J.D. Rimer, Epitaxial growth of ZSM-5@Silicalite-1: A core-shell zeolite designed with passivated surface acidity, ACS Nano. 9 (2015) 4006-4016. doi:10.1021/acsnano.5b01308.

[42] N. Masoumifard, R. Guillet-Nicolas, F. Kleitz, Synthesis of Engineered Zeolitic Materials: From Classical Zeolites to Hierarchical Core-Shell Materials, Adv. Mater. 30 (2018) 1-40. doi:10.1002/adma.201704439.

[43] M. Li, Y. Hu, Y. Fang, T. Tan, Coating mesoporous ZSM-5 by thin microporous Silicalite-1 shell: Formation of core/shell structure, improved hydrothermal stability and outstanding catalytic performance, Catal. Today. (2019). doi:10.1016/j.cattod.2019.02.041. 
[44] P. Dejaifve, A. Auroux, P.C. Gravelle, J.C. Védrine, Z. Gabelica, E.G. Derouane, Methanol conversion on acidic ZSM-5, offretite, and mordenite zeolites: A comparative study of the formation and stability of coke deposits, J. Catal. 70 (1981) 123-136. doi:10.1016/0021-9517(81)90322-5.

[45] M. Stöcker, Methanol-to-hydrocarbons: Catalytic materials and their behavior, Microporous Mesoporous Mater. 29 (1999) 3-48. doi:10.1016/S13871811(98)00319-9.

[46] U. Olsbye, S. Svelle, M. Bjrgen, P. Beato, T.V.W. Janssens, F. Joensen, S. Bordiga, K.P. Lillerud, Conversion of methanol to hydrocarbons: How zeolite cavity and pore size controls product selectivity, Angew. Chemie - Int. Ed. 51 (2012) 5810-5831. doi:10.1002/anie.201103657.

[47] U. V. Mentzel, K.T. Højholt, M.S. Holm, R. Fehrmann, P. Beato, Conversion of methanol to hydrocarbons over conventional and mesoporous H-ZSM-5 and H-GaMFI: Major differences in deactivation behavior, Appl. Catal. A Gen. 417-418 (2012) 290-297. doi:10.1016/j.apcata.2012.01.003.

[48] R. Qi, T. Fu, W. Wan, Z. Li, Pore fabrication of nano-ZSM-5 zeolite by internal desilication and its influence on the methanol to hydrocarbon reaction, Fuel Process. Technol. 155 (2017) 191-199. doi:10.1016/j.fuproc.2016.05.046.

[49] I. Yarulina, A.D. Chowdhury, F. Meirer, B.M. Weckhuysen, J. Gascon, Recent trends and fundamental insights in the methanol-to-hydrocarbons process, Nat. Catal. 1 (2018) 398-411. doi:10.1038/s41929-018-0078-5. 
[50] C.D. Chang, W.H. Lang, R.L. Smith, The conversion of methanol and other Ocompounds to hydrocarbons over zeolite catalysts, J. Catal. 56 (1979) 169-173. doi:10.1016/0021-9517(77)90172-5.

[51] S. Svelle, L. Sommer, K. Barbera, P.N.R. Vennestrøm, U. Olsbye, K.P. Lillerud, S. Bordiga, Y.H. Pan, P. Beato, How defects and crystal morphology control the effects of desilication, Catal. Today. 168 (2011) 38-47. doi:10.1016/j.cattod.2010.12.013.

[52] H. Schulz, "Coking" of zeolites during methanol conversion: Basic reactions of the MTO-, MTP- and MTG processes, Catal. Today. 154 (2010) 183-194. doi:10.1016/j.cattod.2010.05.012.

[53] M. Guisnet, P. Magnoux, Coking and deactivation of zeolites, Appl. Catal. 54 (1989) 1-27. doi:10.1016/s0166-9834(00)82350-7.

[54] D. Mores, E. Stavitski, M.H.F. Kox, J. Kornatowski, U. Olsbye, B.M. Weckhuysen, Space- And time-resolved in-situ spectroscopy on the coke formation in molecular sieves: Methanol-to-olefin conversion over H-ZSM-5 and H-SAPO-34, Chem. - A Eur. J. 14 (2008) 11320-11327. doi:10.1002/chem.200801293.

[55] J.S. Martinez-Espin, M. Mortén, T.V.W. Janssens, S. Svelle, P. Beato, U. Olsbye, New insights into catalyst deactivation and product distribution of zeolites in the methanol-to-hydrocarbons (MTH) reaction with methanol and dimethyl ether feeds, Catal. Sci. Technol. 7 (2017) 2700-2716. doi:10.1039/c7cy00129k.

[56] TOPAS 5.0, B. A., 2012. Available from: http:// www.topas-academic.net/, (2012). 
[57] P. Magnoux, P. Roger, C. Canaff, V. Fouche, N.S. Gnep, M. Guisnet, New technique for the characterization of carbonaceous compounds responsible for zeolite deactivation, Stud. Surf. Sci. Catal. 34 (1987) 317-330. doi:10.1016/S01672991(09)60370-0.

[58] M. Thommes, K. Kaneko, A. V. Neimark, J.P. Olivier, F. Rodriguez-Reinoso, J. Rouquerol, K.S.W. Sing, Physisorption of gases, with special reference to the evaluation of surface area and pore size distribution (IUPAC Technical Report), Pure Appl. Chem. 87 (2015). doi:10.1515/pac-2014-1117.

[59] P.L. Llewellyn, J.P. Coulomb, Y. Grillet, J. Patarin, H. Lauter, H. Reichert, J. Rouquerol, Adsorption by MFI-Type Zeolites Examined by Isothermal Microcalorimetry and Neutron Diffraction. 1. Argon, Krypton, and Methane, Langmuir. 9 (1993) 1846-1851. doi:10.1021/la00031a036.

[60] A.H. Janssen, I. Schmidt, C.J.H. Jacobsen, A.J. Koster, K.P. de Jong, Exploratory study of mesopore templating with carbon during zeolite synthesis, Microporous Mesoporous Mater. 65 (2003) 59-75. doi:10.1016/j.micromeso.2003.07.003.

[61] J. Mielby, J.O. Abildstrøm, S. Pérez-Ferreras, S.B. Rasmussen, S. Kegnæs, Formation of pyridine N-oxides using mesoporous titanium silicalite-1, J. Porous Mater. 21 (2014) 531-537. doi:10.1007/s10934-014-9800-0.

[62] M. Thommes, Physical adsorption characterization of nanoporous materials, Chemie-Ingenieur-Technik. 82 (2010) 1059-1073. doi:10.1002/cite.201000064. 
[63] J.C. Groen, J. Pérez-Ramírez, Critical appraisal of mesopore characterization by adsorption analysis, Appl. Catal. A Gen. 268 (2004) 121-125. doi:10.1016/j.apcata.2004.03.031.

[64] K. Barbera, F. Bonino, S. Bordiga, T.V.W. Janssens, P. Beato, Structuredeactivation relationship for ZSM-5 catalysts governed by framework defects, J. Catal. 280 (2011) 196-205. doi:10.1016/j.jcat.2011.03.016.

[65] R. Buzzoni, S. Bordiga, G. Ricchiardi, C. Lamberti, A. Zecchina, G. Bellussi, Interaction of Pyridine with Acidic (H-ZSM5, H- $\beta$, H-MORD Zeolites) and Superacidic (H-Nafion Membrane) Systems: An IR Investigation, Langmuir. 12 (2002) 930-940. doi:10.1021/la950571i.

[66] F. Schmidt, M.R. Lohe, B. Büchner, F. Giordanino, F. Bonino, S. Kaskel, Improved catalytic performance of hierarchical ZSM-5 synthesized by desilication with surfactants, Microporous Mesoporous Mater. 165 (2013) 148-157. doi:10.1016/j.micromeso.2012.07.045.

[67] U. Olsbye, S. Svelle, K.P. Lillerud, Z.H. Wei, Y.Y. Chen, J.F. Li, J.G. Wang, W.B. Fan, The formation and degradation of active species during methanol conversion over protonated zeotype catalysts, Chem. Soc. Rev. 44 (2015) 7155-7176. doi:10.1039/c5cs00304k.

[68] T.V.W. Janssens, A new approach to the modeling of deactivation in the conversion of methanol on zeolite catalysts, J. Catal. 264 (2009) 130-137. doi:10.1016/j.jcat.2009.03.004. 
[69] S. Lee, M. Choi, Unveiling coke formation mechanism in MFI zeolites during methanol-to-hydrocarbons conversion, J. Catal. 375 (2019) 183-192. doi:10.1016/j.jcat.2019.05.030.

[70] D. Mores, J. Kornatowski, U. Olsbye, B.M. Weckhuysen, Coke formation during the methanol-to-olefin conversion: In situ microspectroscopy on individual H-ZSM-5 crystals with different brønsted acidity, Chem. - A Eur. J. 17 (2011) 2874-2884. doi:10.1002/chem.201002624.

[71] M. Bjørgen, S. Svelle, F. Joensen, J. Nerlov, S. Kolboe, F. Bonino, L. Palumbo, S. Bordiga, U. Olsbye, Conversion of methanol to hydrocarbons over zeolite H-ZSM-5: On the origin of the olefinic species, J. Catal. 249 (2007) 195-207. doi:10.1016/j.jcat.2007.04.006.

[72] F.L. Bleken, S. Chavan, U. Olsbye, M. Boltz, F. Ocampo, B. Louis, Conversion of methanol into light olefins over ZSM-5 zeolite: Strategy to enhance propene selectivity, Appl. Catal. A Gen. 447-448 (2012) 178-185. doi:10.1016/j.apcata.2012.09.025.

[73] D. Rojo-Gama, M. Nielsen, D.S. Wragg, M. Dyballa, J. Holzinger, H. Falsig, L.F. Lundegaard, P. Beato, R.Y. Brogaard, K.P. Lillerud, U. Olsbye, S. Svelle, A Straightforward Descriptor for the Deactivation of Zeolite Catalyst H-ZSM-5, ACS Catal. 7 (2017) 8235-8246. doi:10.1021/acscatal.7b02193.

[74] D.S. Wragg, M.G. O’Brien, F.L. Bleken, M. Di Michiel, U. Olsbye, H. Fjellvåg, Watching the Methanol-to-Olefin Process with Time- and Space-Resolved High-Energy 
Operando X-ray Diffraction, Angew. Chemie Int. Ed. 51 (2012) 7956-7959. doi:10.1002/anie.201203462.

[75] P. del Campo, W.A. Slawinski, R. Henry, M.W. Erichsen, S. Svelle, P. Beato, D. Wragg, U. Olsbye, Time- and space-resolved high energy operando X-ray diffraction for monitoring the methanol to hydrocarbons reaction over H-ZSM-22 zeolite catalyst in different conditions, Surf. Sci. 648 (2016) 141-149. doi:10.1016/j.susc.2015.10.049.

[76] D. Rojo-Gama, S. Etemadi, E. Kirby, K.P. Lillerud, P. Beato, S. Svelle, U. Olsbye, Time- and space-resolved study of the methanol to hydrocarbons (MTH) reaction-influence of zeolite topology on axial deactivation patterns, Faraday Discuss. 197 (2017) 421-446. doi:10.1039/c6fd00187d.

\section{Tables}

Table 1. Textural properties of ZSM-5 zeolites.

\begin{tabular}{|c|c|c|c|c|}
\hline Sample name & $\mathrm{S}_{\mathrm{BET}}{ }^{\mathrm{a}}\left(\mathrm{m}^{2} / \mathrm{g}\right)$ & $\mathrm{S}_{\mathrm{ext}}^{\mathrm{b}}\left(\mathrm{m}^{2} / \mathrm{g}\right)$ & $\mathrm{V}_{\text {micro }}{ }^{\mathrm{b}}\left(\mathrm{cm}^{3} / \mathrm{g}\right)$ & $\mathrm{V}_{\text {tot }}{ }^{\mathrm{c}}\left(\mathrm{cm}^{3} / \mathrm{g}\right)$ \\
\hline Conv-ZSM-5 & 321 & 79 & 0.12 & 0.19 \\
\hline Meso-ZSM-5 & 420 & 150 & 0.11 & 0.29 \\
\hline Shell-Meso-ZSM-5 & 420 & 155 & 0.12 & 0.33 \\
\hline
\end{tabular}

Table 2. Characterization results for ZSM-5 zeolites. 


\begin{tabular}{|c|c|c|c|c|}
\hline Sample name & $\mathrm{Si} / \mathrm{Al}^{\mathrm{a}}$ & $\begin{array}{l}\text { Brønsted acid density } \\
(\mathrm{mmol} / \mathrm{g})\end{array}$ & $\begin{array}{l}\text { Lewis acid density }{ }^{\mathrm{b}} \\
(\mathrm{mmol} / \mathrm{g})\end{array}$ & $\begin{array}{l}\text { Brønsted/Lewis } \\
\text { acid density }\end{array}$ \\
\hline Conv-ZSM-5 & 140 & 0.147 & 0.467 & 0.315 \\
\hline Meso-ZSM-5 & 150 & 0.119 & 0.528 & 0.207 \\
\hline Shell-Meso-ZSM-5 & 163 & 0.106 & 0.537 & 0.197 \\
\hline
\end{tabular}

${ }^{a}$ ICP-OES. ${ }^{b}$ Pyridine-IR

Table 3. Ammonia TPD results.

$\begin{array}{lll}\text { Sample name } & \text { Ammonia uptake }\left(\mathrm{mmol} \mathrm{NH}_{3} / \mathrm{g}\right) & \text { Calculated Si/Al } \\ \text { Conv-ZSM-5 } & 0.121 & 136 \\ \text { Meso-ZSM-5 } & 0.119 & 139 \\ \text { Shell-Meso-ZSM-5 } & 0.086 & 193\end{array}$

Table 4. Lattice parameters calculated for fresh and spent catalyst. The Estimated Standard Deviations (ESDs) on the length of the cell parameters are less than $0.0015 \AA$.

Cell parameters

$\begin{array}{lllll}\text { Fresh catalysts } & a \text {-axis }(\AA) & b \text {-axis }(\AA) & a \text { - } b(\AA) & \text { Cell Volume }\left(\AA^{3}\right) \\ \text { Conv-ZSM-5 } & 20.1077 & 19.8813 & 0.2264 & 5350.86 \\ \text { Meso-ZSM-5 } & 20.1141 & 19.8750 & 0.2391 & 5351.59 \\ \text { Shell-Meso-ZSM-5 } & 20.1127 & 19.8852 & 0.2274 & 5353.77 \\ \text { Used catalysts } & & & & \\ \text { Conv-ZSM-5 } & 20.0792 & 19.9210 & 0.1581 & 5355.86\end{array}$




$\begin{array}{lllll}\text { Meso-ZSM-5 } & 20.0780 & 19.9090 & 0.1690 & 5352.07 \\ \text { Shell-Meso-ZSM-5 } & 20.0890 & 19.8976 & 0.1937 & 5350.65\end{array}$

Figure captions

Fig. 1. Synthesized and tested samples. a) Conventional ZSM-5 (Conv-ZSM-5), b) Mesoporous ZSM-5 (Meso-ZSM-5) and c) Mesoporous ZSM-5 covered with silicalite-1 shell (Shell-Meso-ZSM-5).

Fig. 2. XRD patterns with Rietveld refinements of the three fresh ZSM-5 zeolites.

Fig. 3. $\mathrm{N}_{2}$ adsorption-desorption isotherms of calcined ZSM-5 samples performed at $77 \mathrm{~K}$. Solid and empty symbols correspond to adsorption and desorption, respectively.

Fig. 4. SEM images of conventional ZSM-5 (a,b), mesoporous ZSM-5 (c,d) and mesoporous ZSM-5 with silicalite-1 shell (e,f).

Fig. 5. TEM images of mesoporous ZSM-5 (a,b) and mesoporous ZSM-5 with silicalite-1 shell $(\mathrm{c}, \mathrm{d})$.

Fig. 6. Al 2p scan for surface of mesoporous ZSM-5 and mesoporous ZSM-5 with shell.

Fig. 7. FTIR spectra of ZSM-5 samples after pretreatment (full lines) and after pyridine adsorption (dash line) in the $\mathrm{OH}$ stretching region (left) FTIR spectra of pyridine adsorbed on the zeolites (right). (a) Conv-ZSM-5, (b) Meso-ZSM-5 and (c) Shell-Meso-ZSM-5.

Fig. 8. Ammonia TPD profile of the catalysts. 
Fig. 9. Conversion of methanol as a function of time on stream over different zeolite catalysts at 5 barg and $400{ }^{\circ} \mathrm{C}$ reaction condition for WHSV of $4.7 \mathrm{~g}_{\mathrm{MeOH}} \mathrm{g}_{\mathrm{cat}}{ }^{-1} \mathrm{~h}^{-1}$.

Fig. 10. Cumulative conversion capacity calculated from $100 \%$ to $50 \%$ Conversion using Brønsted acid sites concentration obtained from pyridine IR.

Fig. 11. TGA profiles of deactivated catalysts (the heating rate was $5^{\circ} \mathrm{C} \mathrm{min}^{-1}$ ).

Fig. 12. Chromatograms obtained from the dissolution and coke extraction of three deactivated zeolites. Results are normalized with respect to the internal standard.

Fig. 13. XRD patterns with Rietveld refinements of the three used ZSM-5 zeolites. 
Micropores Micro/mesopores Shell of Silicalite-1

a)

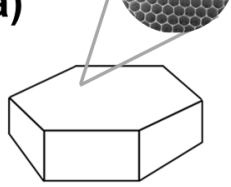

Conv-ZSM-5 b)

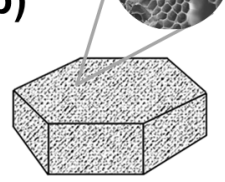

Meso-ZSM-5 Shell-Meso-ZSM-5 c)

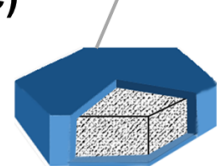




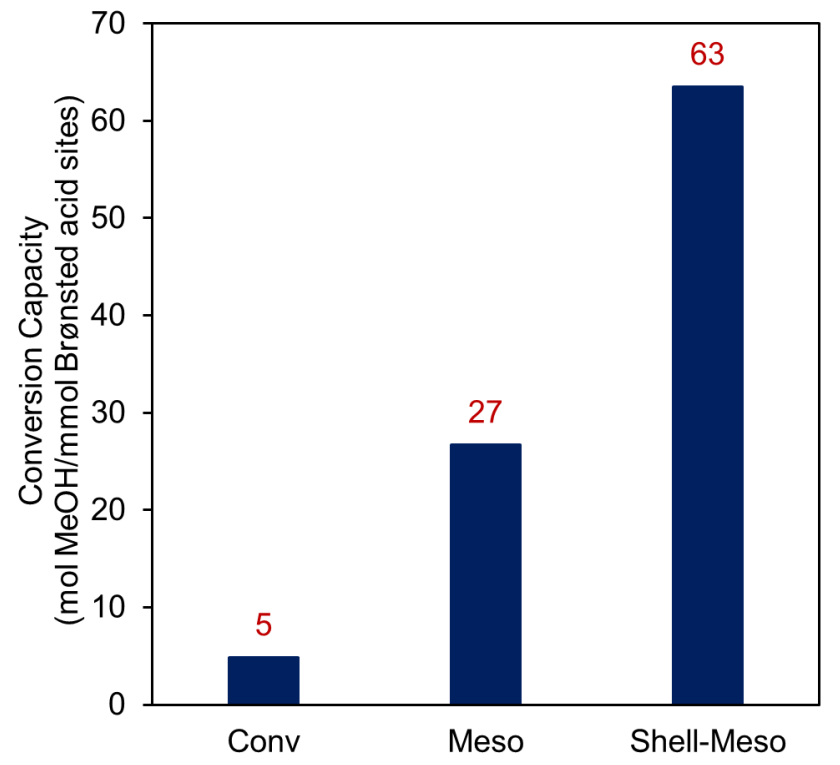




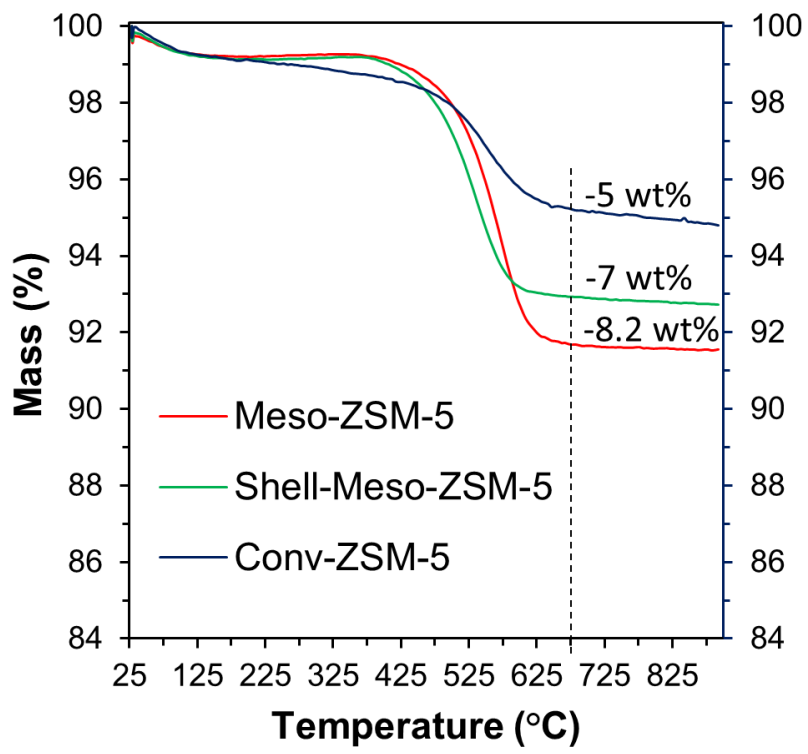




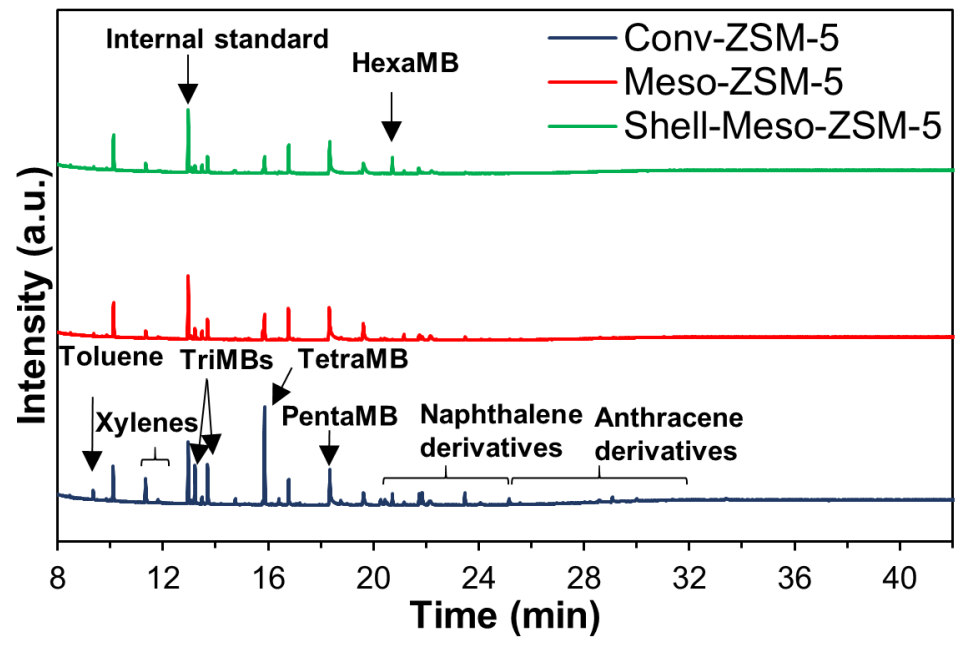




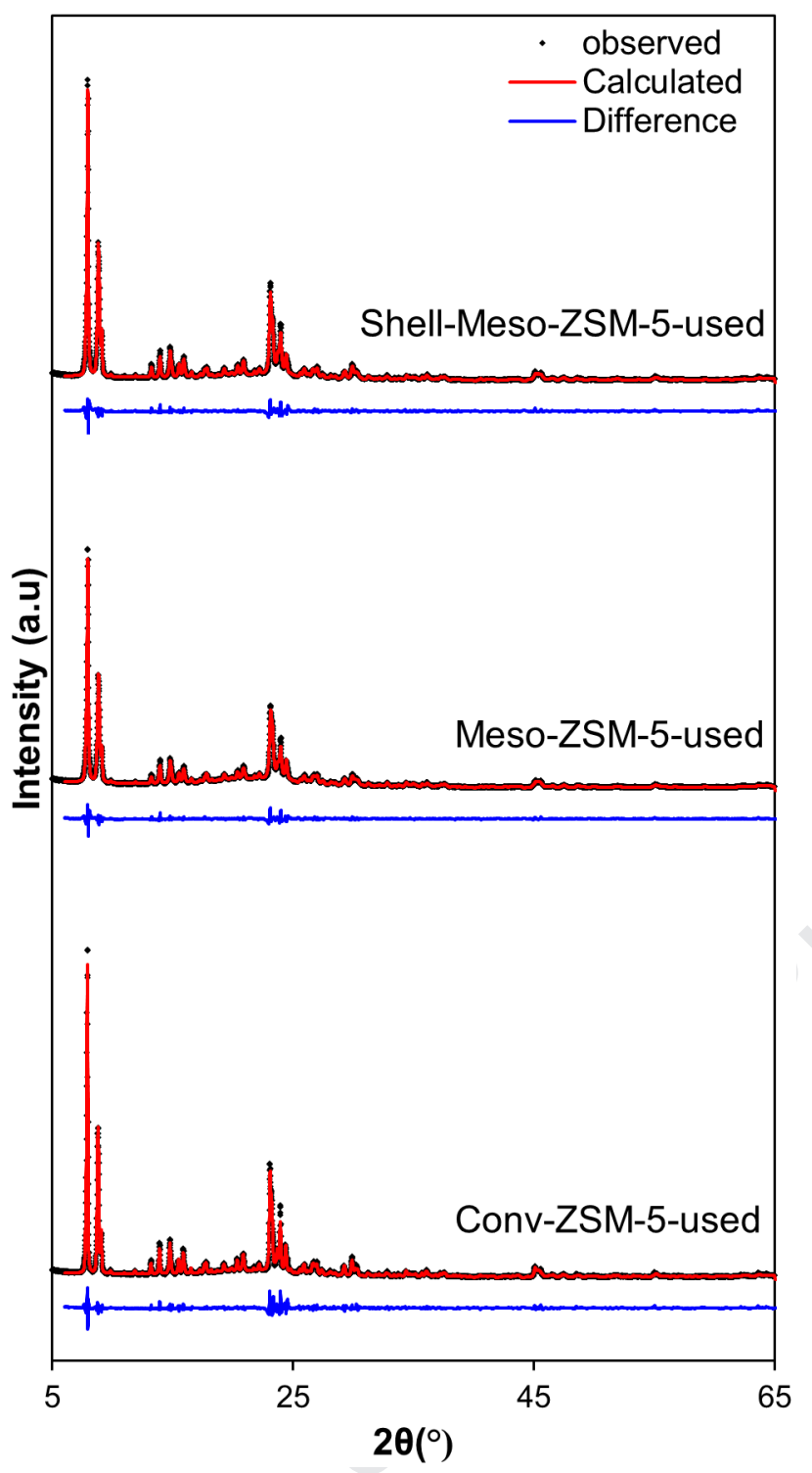




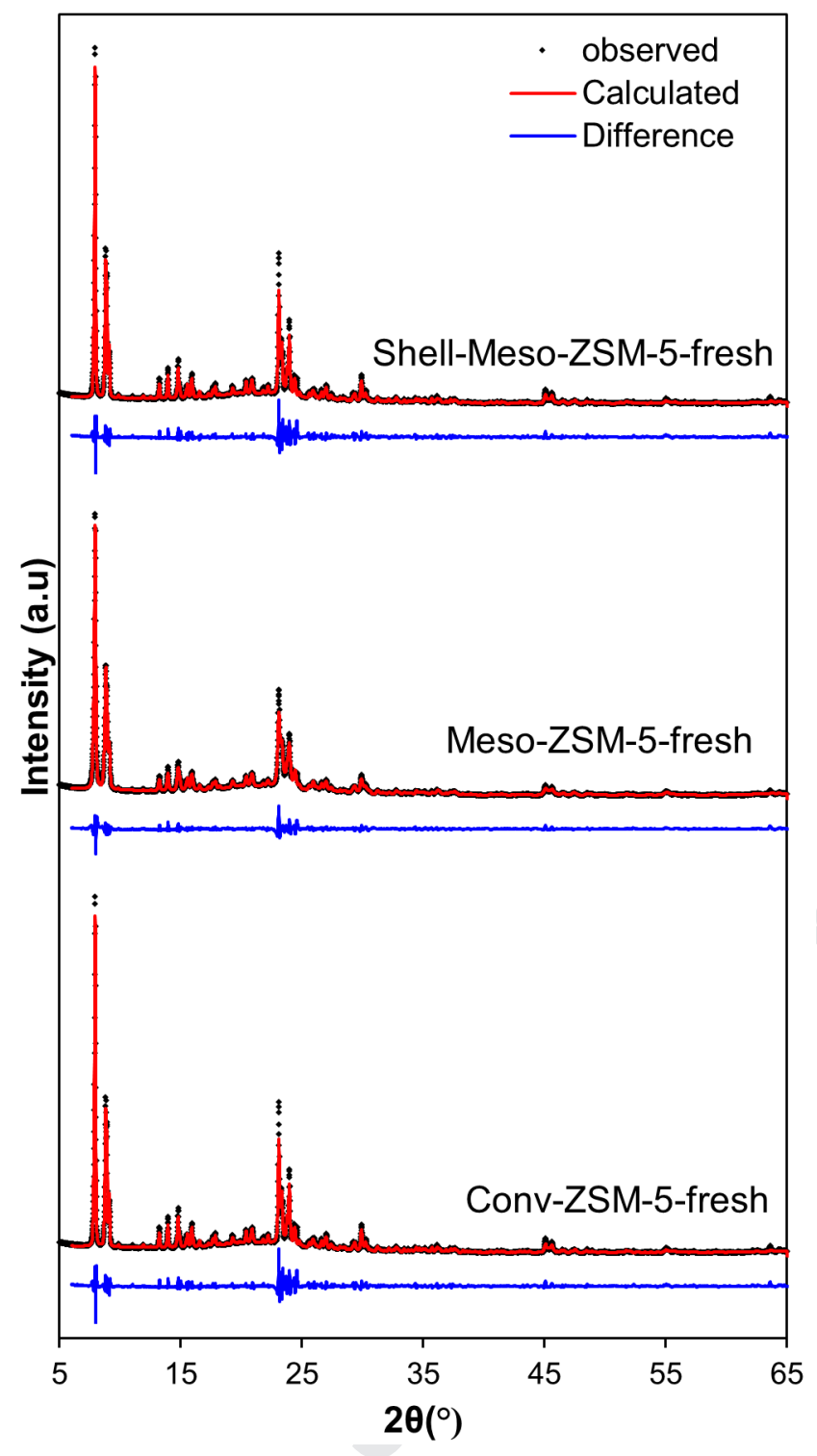




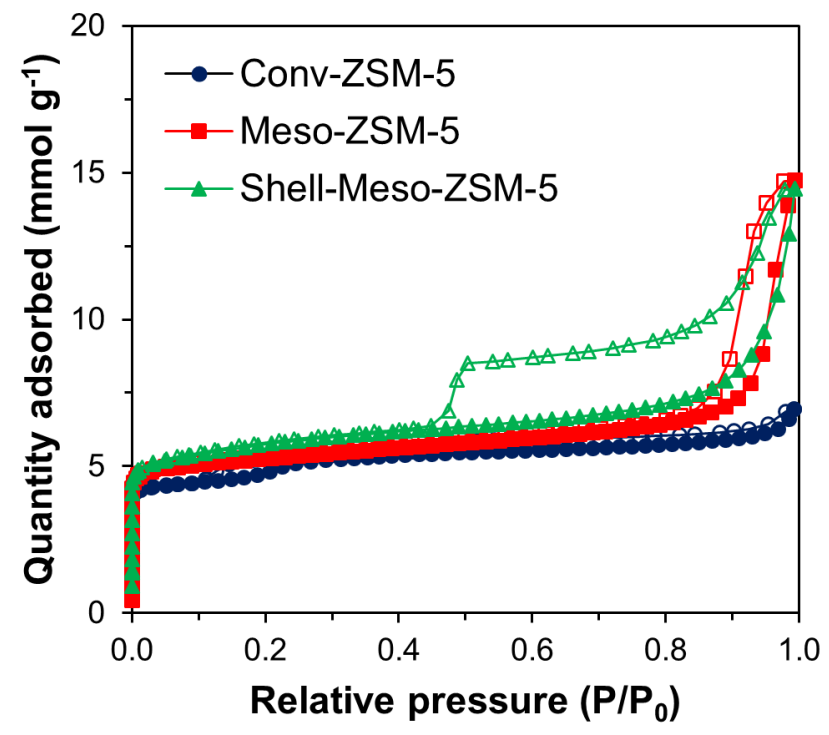



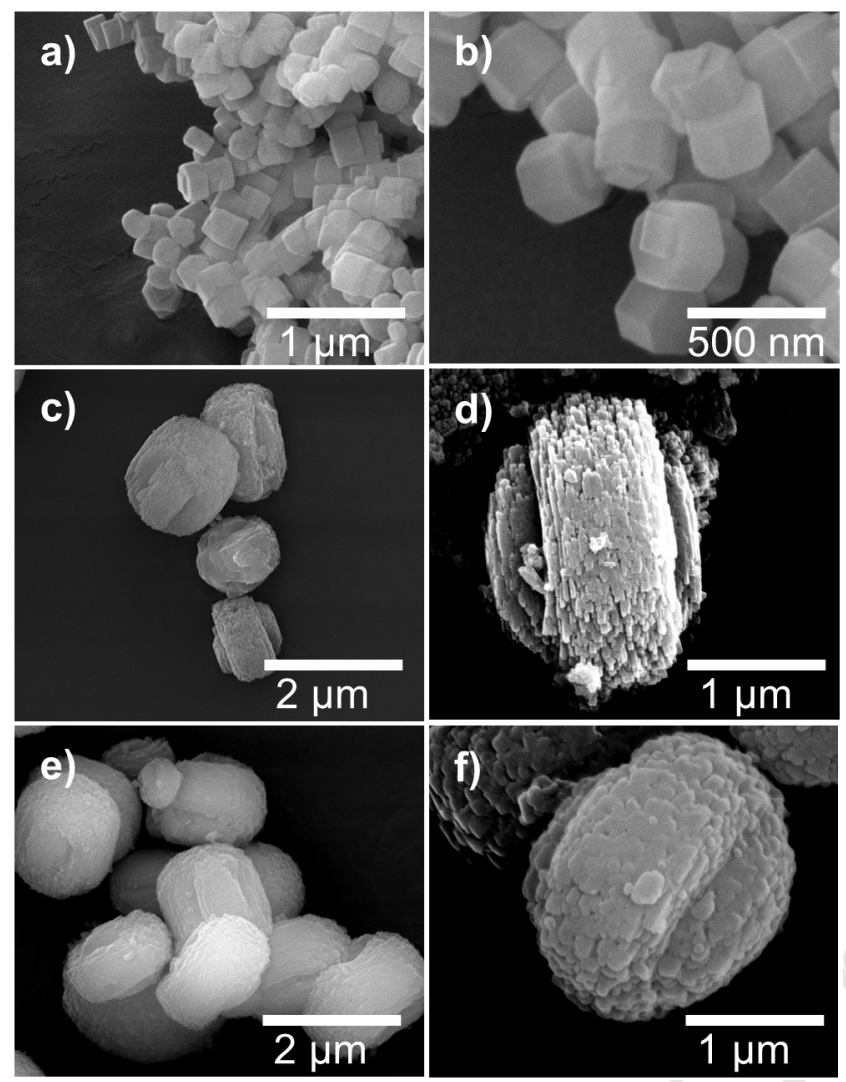


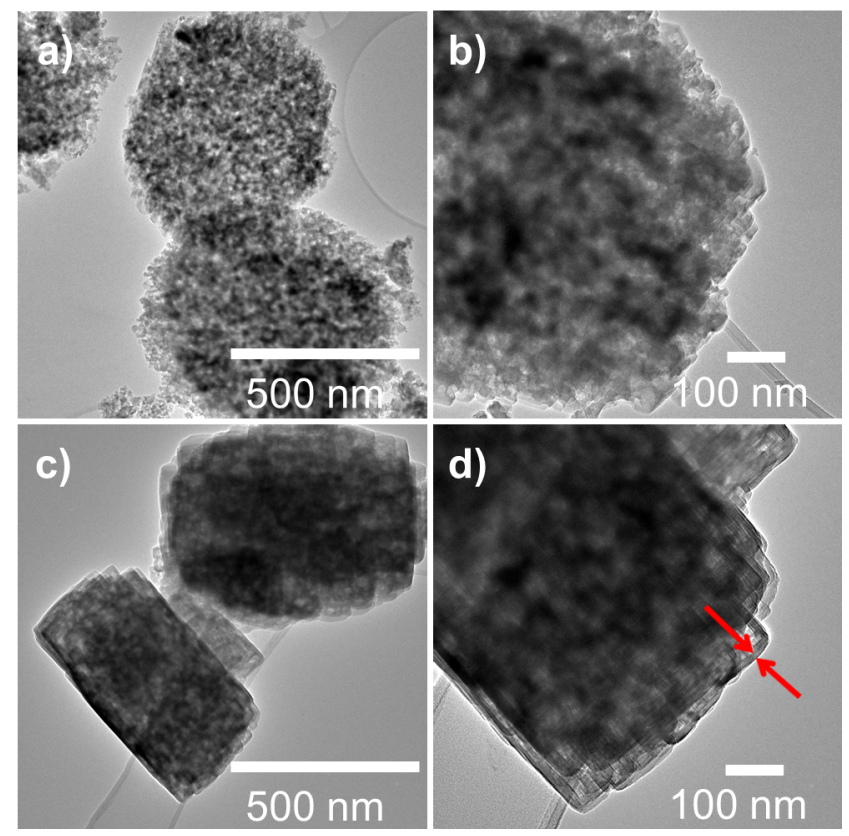




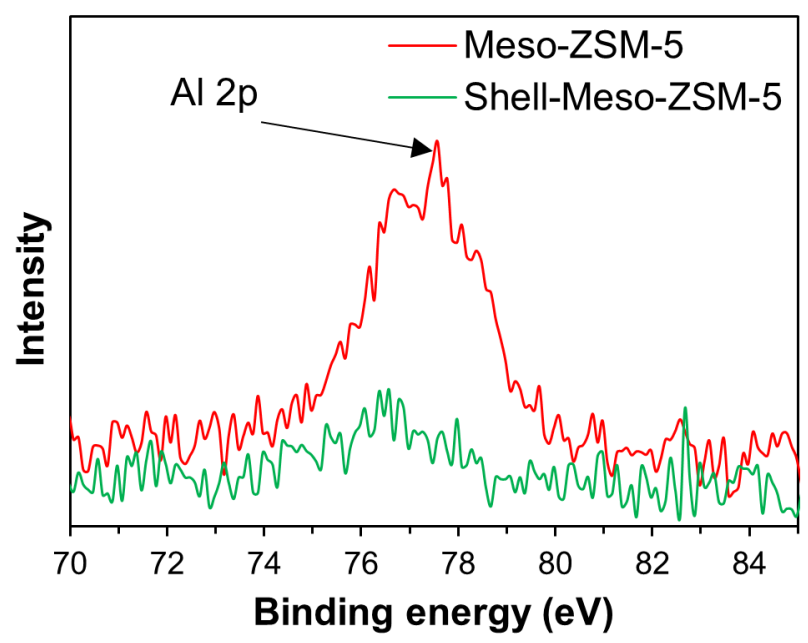



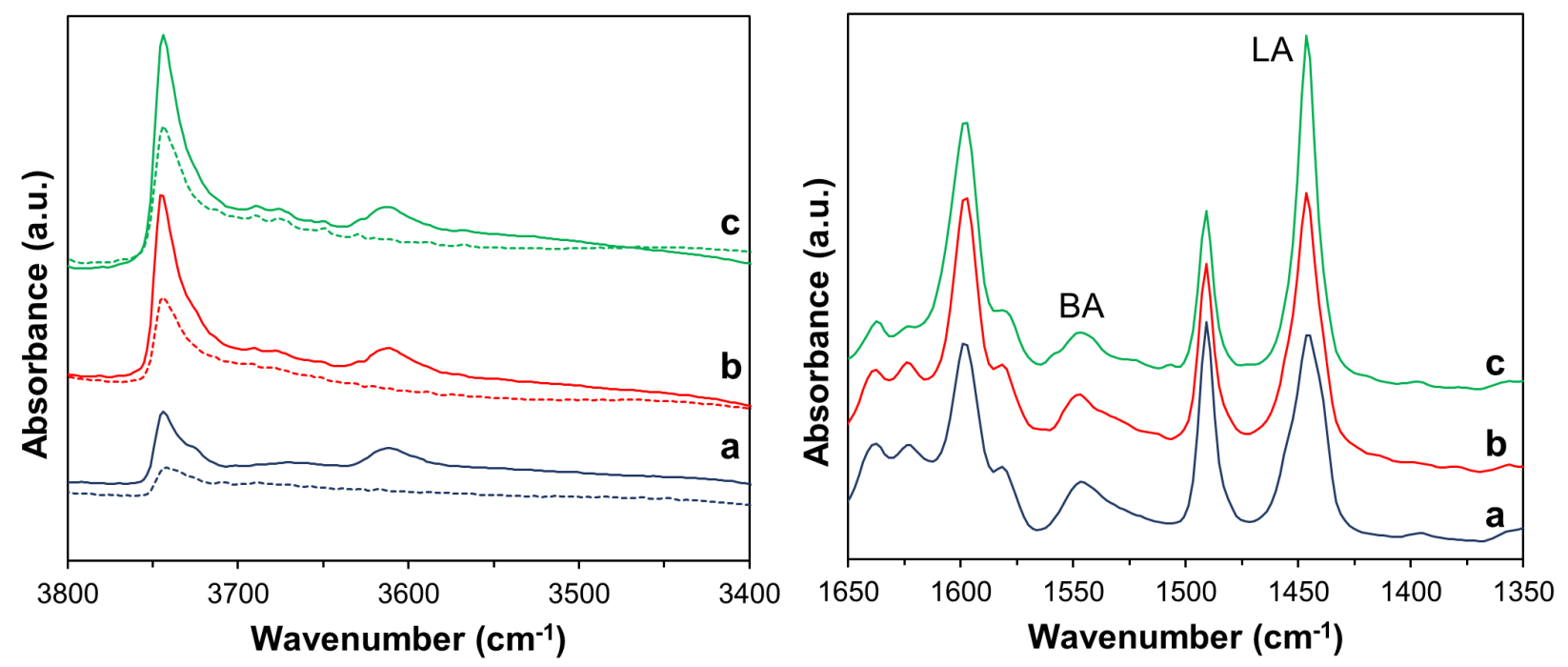


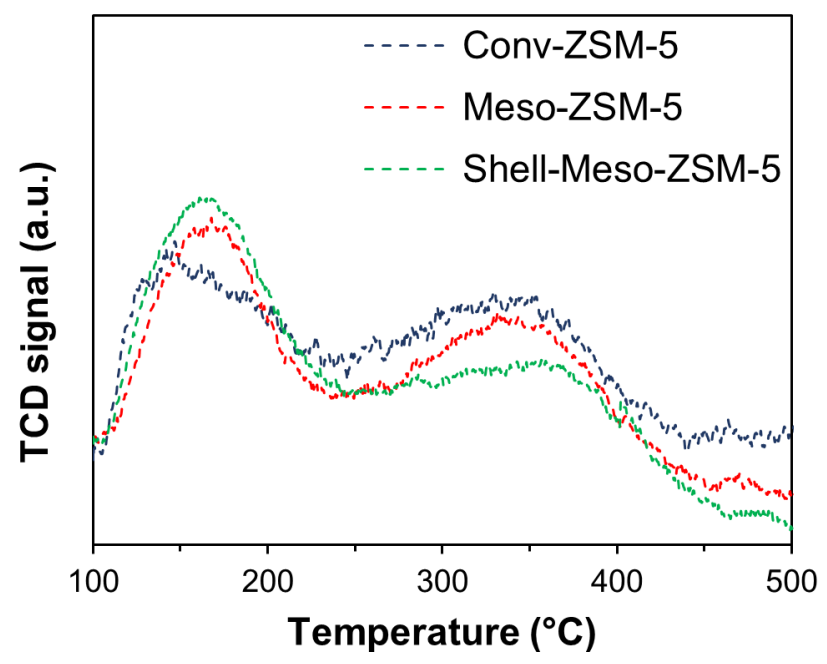




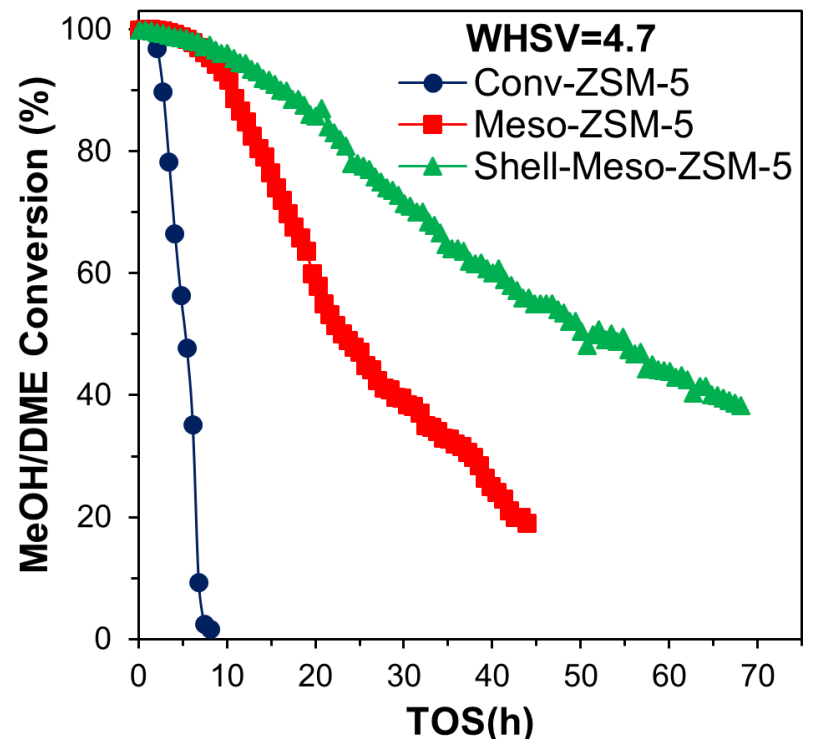


Highlights

- Coating of mesoporous ZSM-5 with ultra-thin silicalite-1 shell via a novel method

- Ultra-thin Al-free shell achieved, recorded by TEM and XPS analysis

- A $100 \%$ increase in catalytic lifetime, proven in MTH under harsh condition

- Minimum structural changes in the catalyst framework by coke deposition 